\title{
Patterns of Plant Adjustment *
}

\author{
Plutarchos Sakellaris \\ University of Maryland and \\ Board of Governors of the Federal Reserve System
}

August 2000

\begin{abstract}
This paper provides a description of the dynamic choices of manufacturing plants when they undertake rapid adjustment in output. The focus is on episodes that involve lumpy adjustment in capital or employment. I examine the behavior of variables such as capital utilization, hours per worker, overtime use, capacity utilization, materials and energy use. Finally I describe the observed patterns of productivity during those adjustment episodes and propose some hypotheses that seem to fit them. The costs associated with output adjustment seem to arise from building and destroying a particular organization of the structure of production and associated worker experience. As such they are related to learning-by-doing and investment in specific training.

Keywords: capital investment, employment adjustment, capacity utilization, productivity, learning effects, specific training.

JEL codes: E22, D24, L60.
\end{abstract}

\footnotetext{
${ }^{*}$ Department of Economics, University of Maryland, College Park, MD 20742 (plutarch@electra.umd.edu). I would like to thank Susan Polatz for outstanding research assistance, John Haltiwanger for providing one of the datasets used here, Lucia Foster for many discussions about the data, Ana Aizcorbe, Roger Betancourt and seminar participants at CES, Federal Reserve Board, and the University of Maryland for useful comments. The data used in this paper were collected under the provisions of Title 13 U.S. Code and are only available at the Center for Economic Studies (CES), U.S. Census Bureau. The research in this paper was conducted by the author as a research associate at the CES. The views expressed here do not represent those of the Board of Governors of the Federal Reserve System, its staff, or the U.S. Census Bureau.
} 


\section{Introduction}

This paper describes the dynamic patterns in plant-level variables during episodes of rapid output adjustment. I analyze two large panels of data on plants in U.S. manufacturing from 1974 to 1991. I identify distinct events of large output adjustment by plants and then study the dynamic choice of different variables around such events. An innovation in this paper is that it brings together data on plant production and operations from different surveys. In addition to output, employment, investment and other variables familiar from the Annual Survey of Manufactures (ASM), I analyze less familiar variables from the Survey of Plant Capacity (SPC) such as capital workquarter, capacity utilization and the use of overtime.

The empirical approach that I employ in this paper is descriptive and non-parametric rather than structural. This seems to be a reasonable approach when attempting a first look at the data. The objective here is twofold. First, I provide some basic facts about the dynamics of lumpy adjustment when alternative margins of adjustment are used by a plant simultaneously. Second, I provide a description of plant productivity growth during those episodes of lumpy adjustment. The uncovered facts shed some light into the nature of the costs associated with output adjustment. These costs seem to arise from building and destroying a particular organization of the structure of production and associated worker experience. As such they are related to learning-by-doing and investment in specific training.

\section{Some related papers on plant adjustment}

The related literature on factor demand is quite voluminous and cannot possibly be summarized here adequately. Hamermesh and Pfann (1996) provide a very good and recent survey. I provide a brief review of a few papers on adjustment at the plant level on which my study builds.

Several papers examined the adjustment of one of the two main factors of production in isolation, either capital or labor. One of the messages of these papers is that adjustment of employment and capital at the plant level is quite lumpy. ${ }^{1}$ These papers do not examine

\footnotetext{
${ }^{1}$ See Hamermesh (1989) or Caballero et al. (1997) for employment and Doms and Dunne (1998) for capital.
} 
the interrelation between capital and employment adjustment at the plant level. ${ }^{2}$ They also do not consider the use of other margins of adjustment available to the plant. ${ }^{3}$

Bresnahan and Ramey (1994) were instrumental in looking inside the "black box" of the plant production function. They demonstrated that a variety of margins is used by plants in order to adjust production. Their focus was on automobile plants and fluctuations at weekly frequencies. They demonstrated that non-convex margins of adjustment, such as plant shutdowns and changes in shiftwork, play a large role in the short-run dynamics of plant output. In many respects, I build on the work of Bresnahan and Ramey (1994). A key difference is that the present paper examines datasets that are representative of the entire U.S. manufacturing sector. An additional difference is that the data used here are annual, for the most part. This allows me to look at medium-run fluctuations in output that may include adjustment in capital. Of course, time aggregation of my data may mask some interesting phenomena that are apparent at the weekly frequency.

Mattey and Strongin (1995) demonstrate why it is important to examine a broad spectrum of manufacturing. They show that manufacturing plants differ quite a bit in how they accomplish output adjustment depending on shutdown cost aspects of their technology. They classify industries into three technology classes: 1) Variable Workquarter with assembly-type operations; 2) Continuous Processing with large shutdown costs; and 3) Other, a category in between the first two. They find that Variable-Workquarter plants accomplish a large part of output adjustments by varying the workperiod of capital whereas continuous processing plants do not.

This paper is also related to Shapiro (1986). Using aggregate data, he estimated how firms use both capital utilization and capital expansion (through investment) in order to respond optimally to shocks. In particular, he showed that temporary shocks are accommodated mostly by adjustment of the workperiod of capital, which he found to be relatively less costly to adjust.

\footnotetext{
${ }^{2}$ As reviewed in Hamermesh and Pfann (1996), however, there are studies that do so for aggregate data.

${ }^{3}$ Caballero et al. (1997), however, do point out that hours per worker are negatively correlated with employment changes.
} 


\section{Data Description}

In this paper I use microdata from the U.S. Census Bureau's Annual Survey of Manufactures (ASM) and Survey of Plant Capacity (SPC). The ASM provides information about U.S. manufacturing plants on an annual basis, drawing upon data from a panel of respondents that is selected every five years. In census years, the ASM data is collected as part of the Census of Manufactures. The SPC collects data on fourth-quarter production levels and other information about operations on a sub-sample of plants in the ASM. From 1974 to 1988, there were three panels in the years 1974-78, 1979-83, and 1984-88. ${ }^{4}$ About threequarters of plants in the SPC remain in the sample for an entire panel. On average, eight to nine thousand plants per year were surveyed for the SPC about their actual operations as well as their "preferred" operations at capacity (see the Appendix for the definition of this notion of capacity). For each of the three panels, there were six to seven thousand plants that provided data for the entire period.

I use two data samples in this paper. The first sample, referred to as BALANCEDLRD, is a panel of ASM respondents that were in continuous operation from 1972 to 1993 (see Cooper et al., 1999 for a more detailed description). Data requirements limited this sample to the years 1974 through 1991 for a total number of 184,916 observations and 10,675 plants. The second sample, referred to as MATCHED, is the subset of plants in BALANCED-LRD that were also respondents in the SPC. The data set was restricted to the years 1979-88 because of the availability of important utilization variables only during these years. ${ }^{5}$ Additionally, only plants that had at least five years of continuous data and non-missing variables were kept. The MATCHED sample contains 9,377 observations and 1,362 plants.

I use throughout the paper a classification of plants according to the production technology in their industry. Three groups are defined: 1) Continuous Processors who face large shutdown costs, 2) Variable Workquarter plants with assembly-type operations, and 3) Other, a category in between the first two in terms of capital utilization patterns. (See

\footnotetext{
${ }^{4}$ The survey continued after 1988 but its sample design and content changed. The information given here is valid for years 1974-88.

${ }^{5}$ Note that all plants in MATCHED are continuous reporters in the ASM by construction. This facilitates the calculation of reliable capital stock variables.
} 
the Appendix for definitions and Mattey and Strongin, 1995 for extensive discussion).

In terms of comparison with the whole manufacturing sector, BALANCED-LRD consists mostly of large plants that account for about $45 \%$ of output in manufacturing. The plants in MATCHED are even larger in size due to the selection process followed here. The sample accounts for about $15 \%$ of manufacturing output on average though this share decreases a bit over time because of attrition. ${ }^{6}$ Certain industries such as Petroleum (SIC 29), and Transportation Equipment (SIC 37) are over-represented in MATCHED. Many others, such as Food (SIC 20), are under-represented. The time series plots of various variables for the average plant in MATCHED and BALANCED-LRD seem to display familiar cyclical patterns.

A key assumption used throughout the paper in the construction of capital is that it takes 1 year to build capital. ASM variables are annual averages whereas SPC variables refer to the fourth quarter of the calendar year. For consistency, I convert fourth-quarter variables to annual averages using the formula: $x_{t}^{\text {average }}=(5 / 8) x_{t}+(3 / 8) x_{t-1}$. In the case of some SPC variables I also report results on fourth-quarter values since they provide some information about the timing of any changes. All results regarding shift use refer to fourth-quarter numbers.

I use the two datasets in parallel for my analysis. The relative advantage of the MATCHED sample is that it contains important variables that may be found only in the SPC. On the other hand, the BALANCED-LRD sample is larger, it covers more years and it is more representative of manufacturing in its size distribution of plants. Thus, when not focusing on SPC variables, I will place more emphasis on results from BALANCED-LRD.

\section{Methodology}

The aim of this paper is to provide some basic facts about how plants use different margins of adjusting their output under different circumstances. The empirical approach that I employ in this paper is descriptive and non-parametric rather than structural. This seems to be a reasonable approach when attempting a first look at the data.

\footnotetext{
${ }^{6}$ This attrition of plants is overwhelmingly due to the requirement that there should be no missing variable of interest in a set of contiguous years with length of at least 5 years. Attrition from the SPC survey is quantitatively much less important.
} 
The strategy I follow is to identify distinct events of large output adjustment by plants and then study the dynamic choice of different variables around such events. I assume that these events were prompted by a large shock to the plant's profitability or the accumulation of a series of shocks to which the plant had not responded previously.

I define three types of rapid and large adjustment. One involves substantial expansion of the capital stock through investment. Following much of the literature I call this a SPIKE. The other two types involve a substantial increase in production worker employment $(P O S E G)$ or a substantial decrease in production worker employment (NEGEG). The exact definitions of these adjustment events are:

- A plant undergoes an equipment investment SPIKE in year $t$ if its equipment investment-to-capital ratio $(I / K)$ is greater than 0.20 and in the preceding year that ratio was less than 0.20 .

- A plant experiences a large increase in employment (POSEG) in year $t$ if the growth rate of production worker employment in $t$ is greater than $10 \%$ and in the preceding year the growth rate is less than $10 \%$ in absolute value.

- A plant experiences a large decrease in employment (NEGEG) in year $t$ if the growth rate of production worker employment in $t$ is less than $-10 \%$ and in the preceding year the growth rate is less than $10 \%$ in absolute value.

Additionally, in order for an observation year to qualify as an event the plant has to have all relevant data for a time window of five years around the event. I denote the year of the event by $t$ and the surrounding years $t-2$ through $t+2$.

Since I do not provide a structural model of plant behavior subject to shocks I have to resort to an ad hoc identification scheme. In particular, I assume that two consecutive years of large adjustment are part of the same adjustment episode. In other words, I exclude the possibility that a substantial shock hits the plant in the calendar year after a lumpy adjustment was undertaken. ${ }^{7}$

\footnotetext{
${ }^{7}$ In the case of investment spikes there is an additional reason for doing so. There is evidence that some plants are recorded as having multi-year spikes (See Cooper et al., 1999). A single spike episode is spread over two consecutive calendar years in the ASM, due to time aggregation in the data and time to build capital.
} 
The results presented below are conditional means of the variables of interest during the five years centered on the event year after controlling for plant and year fixed effects. The model is

$$
X_{i s}=\mu_{i}+\nu_{s}+\sum_{j=-2}^{+2} \beta_{j} \times E V E N T D_{i s}^{t+j}+\beta_{O} \times O T H E R D_{i s}+\epsilon_{i s},
$$

where $X_{i s}$ is one of the variables of interest for plant $i$ in year $s, \mu_{i}$ and $\nu_{s}$ are plant and year fixed effects. The dummy variables $E V E N T D_{i s}^{t+j}$ equals 1 if and only if plant $i$ experienced an event of type $D$ (SPIKE, NEGEG, or POSEG) in year $s-j$. The dummy variable $O T H E R D_{i s}$ equals 1 if and only if plant $i$ has experienced at least one event of type $D$ and any event of type $D$ happened before year $s-2$ or after year $s+2$. It captures the average level of $X$ in years outside the window of event $D$ for plants that experienced at least one event of type $D$. In the case of a stationary variable it provides an indication of the mean that the variable reverts to after the adjustment episode.

Discussion of year effects

The inclusion of fixed year effects is of dual importance. They control for aggregate trends in the variables. More importantly, they control for other aggregate dynamics in the data that may be unrelated to the particular plant-adjustment episode being studied. Of course, to the extent that shocks are aggregate and individual plant response to aggregate shocks is homogeneous the removal of year effects would bias the estimates of dynamic adjustment patterns. This concern, however, is not warranted in my data as the vast majority of the variance in investment and employment is due to idiosyncratic rather than aggregate components.

\section{Discussion of plant heterogeneity}

There is a large literature stressing the importance of heterogeneity among plants in their behavior. The inclusion of a fixed plant effect here is an attempt to control for such heterogeneity even though, by definition, it cannot control for differential dynamic behavior. A way to get around that problem is to split plants according to observable characteristics. I have repeated the analysis after splitting the plants according to whether their technology of production is one of continuous processing, variable workquarter, or other. Another useful split would be by plant size though this would only be applicable for the BALANCED-LRD sample as the plants in the MATCHED sample are uniformly very 
large.

\section{Discussion of definitions}

There is substantial evidence that the employment of non-production workers is smoother than that of production workers. For this reason sharp movements in production worker employment mirror sharp movements in total employment. Since this is true in my data as well, I define POSEG and NEGEG in terms of production workers. The results I present below are not sensitive to the cutoff growth rate in the definitions being increased to 0.15. Additionally, the results are not sensitive to the growth rate of employment being defined as a 4th-quarter to 4th-quarter change instead of a change in the annual averages. The cutoff value for $I / K$ of 0.20 in the definition of a SPIKE has been used by Power (1998) and Cooper et al. (1999). These papers support the choice of the definition for a spike used here and provide evidence of robustness to cutoff levels other than 0.20.

\section{Results}

The sets of graphs that follow display the dynamic behavior of plant variables around lumpy adjustment episodes. I graph the estimated values of $\beta_{t+j}$ ( $j=-2$ to 2$)$ and $\beta_{O}$ as differences from $\beta_{t}$. This re-inforces the fact that due to the inclusion of fixed effects absolute magnitudes are not meaningful per se whereas relative magnitudes are. I also provide the standard error of the $\beta_{t}$ coefficient as an indication of the precision of the estimates.

The standard errors of the other four estimated coefficients, $\beta_{t+j}$, did not differ by more than $15 \%$. For ease of interpretation, I display as much of the quantitative information as possible in graphical form.

\section{$5.1 \quad$ Investment Spikes}

Figures 1 and 2 display the dynamic behavior of plant variables around investment SPIKE episodes. It seems that for the MATCHED sample continuous processing plants are under-represented in the population that experienced spikes, while variable workquarter plants are over-represented. A related fact is that plants that operate three shifts are under-represented in the event population while plants that operate two shifts are overrepresented. These do not hold, however, for BALANCED-LRD. 
Figure 1a contains the frequency distribution of a variable constructed to capture the state of demand facing the plant during the SPIKE episode and contrast it to the distribution of the state of demand in the population. It compares the number of shifts that a plant is employing to the number of shifts it would employ at capacity. When actual shifts are fewer than shifts at capacity the plant must be experiencing a low state of demand. This corresponds to states 2 and 5 (see the Appendix for the exact definition). Conversely, when actual shifts are more than shifts at capacity the plant must be experiencing a high state of demand (states 3 and 6). The choice of shiftwork in states 1, 4, and 7 signals a "normal" state of demand. ${ }^{8}$ In the case of investment spikes, shift behavior does not change very much (see evidence below) so this measure is not very informative. Still, there is mild evidence that before the SPIKE more plants face high demand than afterwards.

The investment rate during a SPIKE year is substantially higher than in the adjacent years and drops only gradually towards its level in $t-1$ (Figures $1 \mathrm{~d}, 2 \mathrm{c}$ ). This is very interesting as it provides prima facie evidence that lumpy adjustment is preceded and followed by smooth adjustment. ${ }^{9}$ The natural conclusion is that both non-convex and convex costs of adjusting capital are important for plant investment decisions. ${ }^{10}$

The growth rate of output is positive both before and after the spike (Figures 1c, 2b). Plants grow on average before the spike in terms of both labor and capital input (Figures 1d, 1f, $2 \mathrm{c}, 2 \mathrm{e})$. In fact, the capital-labor intensity falls before the spike, indicating that plants increase their labor input, a relatively more flexible factor, in anticipation of the massive capital build-up (Figures 1h, 2g). Overtime hours are used more intensively especially during the spike and there is mild evidence that hours per worker are heightened before

\footnotetext{
${ }^{8}$ Bresnahan and Ramey (1994) find that changes in actual number of shifts are long-lasting and indicate large swings in demand facing the plant. The idea is that variation in the number of shifts is subject to significant fixed costs. This is the motivation for the measure I use here. However, I compare shiftwork at two different levels of production at a given point in time that rather than over two consecutive periods since I do not have high-frequency data at my disposal.

${ }^{9}$ It is important to note that the pattern shown here is not generated by a varying intensity of plants switching between two states of investment activity: one of inactivity and one of a discrete spike. About $50 \%$ of the plants involved in a SPIKE have investment rate between 0.10 and 0.20 in $t-1$. For $t+1$ and $t+2$ the corresponding fraction is about $30 \%$ and $25 \%$. A similar statement can be made for the share of plants that have investment rate between 0.02 and 0.10 .

${ }^{10}$ The strength of this conclusion is mitigated by possible measurement problems that lead to a single spike being spread over two consecutive years. Note, however, that such "multiyear-spike" problems do not influence $t+2$ investment, which is quite elevated compared to $t-2$ investment.
} 
the spike (Figures 1j, 2f). Capital utilization, as measured by the workquarter of capital, also increases before and during the spike (Figure 1k). After the spike, the capital-labor intensity rises even though employment continues to increase. The use of overtime hours, hours per worker, the workquarter of capital all fall after the spike. Another interesting observation is that the materials to capital use and electricity to capital use rise before the spike and drop sharply there, while the ratio of materials and energy to labor is flat throughout (Figures 1h, 2g).

The typical plant experiencing a spike increases its output by about $9 \%$ in the four years between $t-2$ and $t+2$ (10\% in the BALANCED- LRD). In fact, the data show that the annual rate of growth is as high between $t-3$ and $t-2$. The data seem to distinguish roughly three stages to this adjustment episode. First, growth is achieved through a gradual increase in employment. At the same time, the intensity of use of flexible factors of production, such as materials or energy, is increased relative to quasifixed factors such as capital or labor (note the comparison with "other" in Figures 1i and $2 \mathrm{~g}$ ). Second, this prolonged growth leads to the investment spike, which increases the capital-labor intensity dramatically. Around the time of the spike there is heightened use of temporary margins of adjustment such as the workquarter of capital, hours per worker, and overtime hours. Third, after the spike the intensity of use of materials and energy drops as does the use of the temporary margins listed above.

\section{Some observations on the utilization of capital and capacity}

Curiously enough, there are about as many plants that drop shifts during a spike as there are that add shifts (see Figure 11). ${ }^{11}$ About $85 \%$ of them do neither. This heterogeneity in shift behavior merits further study. Variable workquarter plants use shifts far more heavily than do other plants in order to achieve workquarter changes (Figure 1m). Capacity utilization is heightened and flat before and during the spike but falls significantly afterwards. Thus, after a spike output growth is negatively correlated with capacity utilization at the plant level. This is in sharp contrast to the well-known positive correlation in aggregate data between output growth and capacity utilization.

Finally, the data shed some light into the assumption that energy or materials use may

\footnotetext{
${ }^{11} \mathrm{~A}$ related fact is that a SPIKE is about as likely to be accompanied by a POSEG as by a NEGEG event.
} 
proxy for capital utilization. This assumption was formalized by Jorgenson and Griliches (1967) and Burnside et al. (1995) as: Capital Services $=\min \{K \times U, P\}$, where $U$ is capital utilization and $P$ is the proxy. Optimizing plants, then, choose $P=U \times K$, a prediction that is not validated in the data when using either materials or energy for $P$ and the workquarter for $U$. This may be seen in Figure 1.i, which shows that the ratio of the proxy to capital services $(K \times U)$ is far from constant during the average SPIKE episode. This is true even for variable workquarter plants where identifying $U$ with the observable workquarter seems reasonable (see Figures $1 . \mathrm{u}$ and $1 . \mathrm{w}) .{ }^{12}$

\section{$5.2 \quad$ Large Decreases in Employment}

Figures 3 and 4 display the dynamic behavior of plant variables around episodes of lumpy decreases in employment (NEGEG). In both samples, the plants that reduce their employment dramatically seem to be quite representative of the population in terms of technology class and the number of shifts they use. These episodes are characterized by dramatic collapses in output (Figures 3c, 4b): $15 \%$ between $t-2$ and $t$ (17\% in BALANCED-LRD). After the massive firings output stabilizes.

The variable capturing state of demand based on shift behavior sends very clear signals (Figure 3a). The proportion of plants facing low demand (states 2 and 5) increases dramatically at $t$ and, correspondingly, the proportion of plants facing high demand (states 3 and 6) falls to nearly zero. However, some of these changes are short-lived and do not persist into the following year or two.

The reduction in output is achieved mostly through reduced employment of both production and non-production workers (Figures 3e, 3f, 3g, 4d, 4e, 4f). The pattern of adjustment, however, is markedly different for these two groups. Almost all of the reduction in production workers is achieved in one year, between $t-1$ and $t$. For non-production workers, instead, the adjustment seems to be relatively smooth over the five observed years and only seems to intensify a bit at $t+1 .^{13}$ This accords with many studies finding that non-production workers are more costly to adjust than production workers. By the end

\footnotetext{
${ }^{12} \mathrm{Basu}(1995)$, however, proposes a different formulation for capital services that constrains the elasticity of the proxy with respect to $K \times U$ to be constant but not necessarily unitary. This formulation can be tested also by identifying $U$ with the observable workquarter.

${ }^{13}$ Behavior between $t-3$ and $t-2$ may be read from graphs of the growth rate.
} 
of $t+2$, the skill ratio has increased but this could be because the adjustment of nonproduction workers is not complete yet. The investment rate does not fall much during the episode yet capital seems to fall a bit by $t+2$ (Figures $3 \mathrm{~d}, 4 \mathrm{c}) \cdot{ }^{14}$

Energy use and materials use show a great deal of flexibility (Figures 3h, 4g). Their ratio to capital falls in $t$, the fall being disproportionately larger for materials. This is a puzzle within a framework of a CES production function if all factors are flexible and there are no systematic movements in their relative prices. The puzzle may be resolved, however, by considering that the capital stock is considerably less flexible (more quasifixed) than labor, or materials. Thus, labor and materials respond more promptly to shocks with capital response lagging. Variations in energy-capital ratios track very closely the workquarter of capital for variable-workquarter plants (Figure 3u).

The workquarter of capital falls quite dramatically between $t-2$ and $t$ (about $4.5 \%$ ) and stays at low levels for two more years (Figure 3k). About $10 \%$ of the plants reduce their shifts by the event year, $t$, and these changes seem to persist until $t+2$ (Figure 31 ). There is also a small fraction of plants which, having added shifts a year before the event $(t-1)$, display only a temporary decrease in shifts in $t$. Shift changes account for about $20 \%$ of workquarter changes at $t$ though this number varies greatly by technology class (Figure $3 \mathrm{~m}$ ). For variable workquarter plants the proportion is about $35 \%$ whereas for continuous processors it is zero. The importance of changes in shift use for decreasing the workquarter explains to some extent the persistence in the reduction of the workquarter.

Hours per worker and overtime use fall temporarily before $t$ (Figure $3 \mathrm{j}$ ). Hours per worker recover promptly as employment drops. ${ }^{15}$ The well-known fact that aggregate hours per worker fall in recessions should be contrasted with the pattern observed at the plant level during rapid employment contractions. After the bulk of the adjustment in employment has been completed, hours per worker return to higher levels even though output stays at low levels. Capacity utilization falls about seven percentage points between $t-2$ and $t$ and starts to pick up only towards the end of $t+1$ (Figure $3 \mathrm{n}$ ). The correlation between plant output and capacity utilization is clearly positive during this adjustment episode in

\footnotetext{
${ }^{14}$ This may be ascertained by comparing the observed decrease in employment to the observed capitallabor intensity.

${ }^{15}$ This dynamic pattern underlies the finding in Caballero et al. (1997) of negative correlation between hours per worker and employment.
} 
contrast to what is observed after an investment spike.

\subsection{Large Increases in Employment}

Figures 5 and 6 display the dynamic behavior of plant variables around episodes of lumpy employment increases (POSEG). In both samples, continuous processors are substantially under-represented in the event population compared to the total population. Variableworkquarter plants, on the contrary, are substantially over-represented. The imbalance is most pronounced in the MATCHED sample.

Annual output grows by $24 \%$ in MATCHED (20\% in BALANCED-LRD) between $t-2$ and $t+1$ (Figures $3 \mathrm{c}, 4 \mathrm{~b}$ ). As was the case with NEGEG events, employment adjustment is the main margin for output adjustment. Production workers increase by about $29 \%$ (25\% in BALANCED-LRD) and this adjustment is quite rapid (Figures 5e, 5f, 6d, 6e). In BALANCED-LRD it is accomplished within a year! In contrast, non-production workers' adjustment is smooth and drawn out over at least four years. By the end of $t+2$, the skilled workers' share of employment decreases by about $11 \%$ though this may reflect that hirings of non-production workers are planned to continue beyond $t+2$ (Figures 5g, 6f). Investment rates go up by about 4 percentage points (in BALANCED-LRD) between $t-2$ and $t$ and then come down (Figures $5 \mathrm{~d}, 6 \mathrm{c}$ ). The resulting increase in the capital stock is not enough sufficient to prevent the capital-labor intensity from decreasing about $12 \%$. There is some indication, however, that this intensity keeps going up after $t+2$ through smooth increases in the capital stock by plants. This is consistent with the existence of significant convex costs in adjusting capital.

Regarding the adjustment of materials and electricity the observed dynamic patterns are almost mirror images of those observed in NEGEG (Figures 5h, 5i, 6g). Materials use moves almost in lock-step with labor hours, whereas energy moves proportionately less. Thus, the puzzle regarding CES production function predictions when inputs are fully flexible appears here too.

Hours per worker and overtime use are heightened just before the massive hirings and they fall afterwards (Figures 5j, 6f). As in NEGEG the use of the hours-per-worker margin is relatively short-lived. The workquarter of capital increases a bit and stays high facilitating increased capital services (Figure 5k). About $11 \%$ of the plants increase the number of 
shifts between $t-2$ and $t+2$ (Figure $5 \mathrm{l}$ ). Interestingly, some $3 \%$ of plants decrease shifts between $t-2$ and $t-1$ and maintain lower shifts even as they add extra workers later. The dynamic pattern of capacity utilization is the same as that of output leading to a strong positive correlation between the two variables (Figure 5n).

\subsection{Contrasting Employment-adjustment to Capital-adjustment Episodes}

A key differentiating fact in the output adjustment episodes I study in this paper is that those based primarily on lumpy changes in employment achieve a considerably greater output change. The average output change between $t-2$ and $t+2$ is about $10 \%$ for SPIKE as opposed to about $-20 \%$ for NEGEG and about $20 \%$ for POSEG. ${ }^{16}$

In both types of episodes there is a multitude of adjustment margins used. Some are temporary such as overtime use and hours per worker. In the case of hours per worker, they reach their peak (or trough) the year prior to a lumpy employment adjustment but contemporaneously with a lumpy capital adjustment. The workquarter of capital and shift use are also varied during the episodes studied here with different levels of persistence. Changes in the workquarter tend to be temporary during a SPIKE in investment while they tend to persist during lumpy employment adjustment (NEGEG and POSEG). A factor contributing to this difference is that the latter episodes involve considerable use of shift changes.

Of course, the main margins used in these episodes are capital and labor, by definition. Changes in these factors seem to be long-lived and they are executed in both lumpy and smooth fashions (sometimes even within the same episode).

\section{$6 \quad$ Productivity growth}

I now focus on the behavior of plant productivity during episodes of extreme adjustment. Given the evidence of procyclical labor productivity (LP) in aggregate data, one might expect that when a plant increases output its productivity rises too and vice versa. ${ }^{17}$ No

\footnotetext{
${ }^{16}$ These figures are for the BALANCED-LRD sample.

${ }^{17}$ Of course, it could be the case that the procyclical aggregate pattern is due to resource reallocation between establishments over the business cycle (see Basu and Fernald, 1997). In other words, the within
} 
such monotonic pattern emerges at the plant level (Figures 1p, 2i, 3p, 4i, 5p, 6i). In fact, labor productivity at the plant level during a spike episode stays rather flat until the new capital is installed and then drops temporarily. During an employment reduction episode (NEGEG) labor productivity actually rises while it falls during an employment expansion (POSEG). In order to understand these patterns better we need to examine the behavior of total factor productivity (TFP).

\subsection{Investment spikes and TFP}

Total Factor Productivity (TFP) shows a precipitous drop of about $4 \%$ one year after the spike for plants in MATCHED. ${ }^{18}$ It starts to recover slowly about two years after the spike. ${ }^{19}$ Adjusting for capital utilization, as measured by the workquarter of the plant, does not change this pattern. What could explain this large drop and subsequent slow recovery in TFP?

Mismeasurement in the capital stock

Suppose that the plant finds it optimal to retire some old equipment at the same time that it augments its stock with new equipment. The perpetual inventory method used in the construction of the capital stock, $K$, would not reflect this retirement and TFP would be biased downward. This argument is plausible, though, as I show below, it can explain at best a small fraction of the TFP drop. The familiar growth accounting formula is

$$
\Delta t f p=\Delta y-\alpha \Delta u-\alpha \Delta k-\beta \Delta l-\gamma \Delta m
$$

where $\Delta$ is the first-difference operator, $t f p, y, u, l, k, m$ refer to logs of TFP, gross output, workquarter of capital, labor input, measured capital stock, and materials respectively, and $\alpha, \beta, \gamma$ are their respective elasticities.

Using the average numbers contained in the figures for the MATCHED sample and setting $\alpha=0.10, \beta=0.35$, and $\gamma=0.55$ as average shares the identity holds exactly for a measured TFP growth between $t$ and $t+2$ of $-4.1 \%$. Suppose that the plant retired $8 \%$ of its old capital contemporaneously with the spike. Then, correctly measured capital in $t+1$

\footnotetext{
variation is overwhelmed by the between variation.

${ }^{18}$ In the BALANCED-LRD sample the drop is $1.7 \%$ in $t+1$ and an additional $0.4 \%$ in $t+2$.

${ }^{19}$ This slow recovery is evident in both MATCHED and BALANCED-LRD. TFP grows by about $0.5 \%$ between $t+2$ and $t+3$.
} 
would be only $95 \%$ of measured capital. ${ }^{20}$ The corresponding TFP growth rate would still be $-3.6 \%$. If the average plant retired $16 \%$ of its old capital, instead, a rather unrealistic assumption, ${ }^{21}$ the TFP growth would be $-3.0 \%$, still substantial. ${ }^{22}$

To conclude, mismeasurement of the capital stock due to retirement seems to play little role in the drop of TFP after an investment spike.

\section{Embodied Technology and Learning Effects}

An attractive hypothesis is that the investment spike involves the introduction in the plant of new technology embodied in the installed equipment. In the early phases of its incorporation into production this new technology may be operated inefficiently because new skills and experience need to be developed gradually. The result is a drop in TFP immediately after the introduction of new technology with gradual recovery ensuing thereafter. Greenwood and Jovanovic (1998) present a nice aggregate model for this hypothesis, which I adapt and simplify here to model plant productivity in isolation. ${ }^{23}$

Consider a plant that lives for three periods $(t=0,1,2)$ and is endowed with capital stock $k_{0}$. The plant decides how much to produce and how much to invest at $t=0$ and $t=1$. Each vintage of capital lasts for two periods only (one-hoss-shay depreciation). The plant only produces at $t=2$ but does not invest as it takes one period to build new capital. Production with every vintage is additively separable and is given by: $y_{v, t}=z_{v, t} k_{v}^{\alpha} l_{v, t}^{1-\alpha}$, where $v=0,1$ denotes vintage, and $z$ is vintage-specific TFP. I assume that the new vintage of capital, $k_{1}$, embodies new technology that makes it more productive than the same amount of investment of old vintage. In particular 1 unit of the new vintage is equivalent to $q$ units of old vintage in terms of productive efficiency $(q>1)$. The plant

\footnotetext{
${ }^{20} \mathrm{I}$ calculated this under the assumption that the exponential depreciation rate is $10 \%$ and the average investment rate during a spike is 0.40 .

${ }^{21}$ I looked at capital retirement data (when available) for 1973-88 for BALANCED-LRD. Equipment retirements average about $4.6 \%$ during a SPIKE whereas structures retirements about $3.1 \%$. These numbers are slightly lower when not restricting to SPIKE years. The distribution of retirements is very skewed. For example, $74 \%$ of plants have equipment retirements between 0 and $4 \%$ whereas $10 \%$ of plants have equipment retirements greater than $10 \%$.

${ }^{22}$ I performed a similar counterfactual experiment for BALANCED-LRD with similar results. For example, allowing $8 \%$ retirements on average during a SPIKE reduces $t$-to- $t+2$ drop in TFP by about 17 percent only. Finally, I repeated this exercise at the plant level to avoid possible aggregation biases with similar conclusions.

${ }^{23}$ The above paper also contains many references to other papers developing and providing evidence for the hypothesis of investment-specific technological change and learning effects.
} 
managers know this but growth accountants may not. Finally, I model learning effects with the assumption that whereas $z_{0,0}=z_{0,1}=Z$, the new vintage has a lower TFP temporarily for its initial period of operation: $z_{1,1}=(1-\kappa) Z$, and $z_{1,2}=Z$.

I do not model why the plant invests and how much as it is not necessary in order to calculate productivity growth. Instead, I assume that the plant invests $\gamma k_{0}$ so that (mis-) measured $\hat{k}_{1}=\gamma k_{0}$ whereas true $k_{1}=\gamma q k_{0}$. One can show that due to equalization of the marginal product of labor across vintages, average labor productivity is constant as long as the real wage rate is constant. Mis-measured TFP growth between $t=1$ and $t=2$ is $-\alpha \log (R)$ where $R=[1+\gamma] /\left[1+q \gamma(1-\kappa)^{1 / \alpha}\right]$. It is clear from this expression that in the absence of learning effects, $\kappa=0$, an increase in TFP should be observed. A drop can only be observed if $q(1-\kappa)^{1 / \alpha}<1$, that is, if the learning effect is steep enough. Correctly-measured TFP growth is $-\alpha \log (\hat{R})$ where $\hat{R}=[1+q \gamma] /\left[1+q \gamma(1-\kappa)^{1 / \alpha}\right]$. So, true TFP stays constant after a spike if $\kappa=0$ but drops if $\kappa>0$.

\section{Related Observations}

The fact that labor productivity shows a temporary decline as well, provides additional corroborating evidence for learning effects. It also indicates a possible failure to equalize the marginal product of labor across vintages. Most likely, the assumption of perfect ex post flexibility in substituting labor for capital is violated. An example of such a violation would be if workers and machines were combined in fixed proportions.

It is noteworthy that plants increase the share of non-production workers in employment after a spike. ${ }^{24}$ This share increases by $1.5 \%$ two years after the spike (Figure $2 \mathrm{f}$ ). Various studies have argued that this share is a measure of the relative level of skill of a plant's labor force. Thus, the increase in the share of non-production workers after a spike may be seen as evidence for hypotheses that posit that skilled labor is more efficient at adopting a new technology or using capital in general.

\subsection{TFP during Lumpy Employment Adjustment}

During episodes of lumpy decreases in employment (NEGEG) TFP displays what may be described best as a "V"-shaped path with the trough being in the event year (Figures 3p, 4i).

\footnotetext{
${ }^{24}$ This is true in BALANCED-LRD though not in MATCHED.
} 
The "V"-shaped path in productivity together with the "L"-shaped path in output imply that during extreme reductions in plant employment, productivity and output show two distinct patterns of comovement. Before and during the event, output and productivity show a pronounced positive comovement whereas afterwards this is not the case. The simple pattern of procyclical productivity in aggregate data is not observed at the plant level. The sharp drop in TFP in the event year, even adjusted for capital utilization, and subsequent recovery seems to be evidence for the importance of internal adjustment costs associated with changes in the scale of operations. Changes in the size of the workforce reduce productivity temporarily as plants rearrange and disrupt the production process. ${ }^{25}$ The evidence for internal adjustment costs is strengthened when one considers that plants are most likely to be firing workers with relatively low productivity.

It is interesting to note that plants whose technology is classified as OTHER do not experience this drop and subsequent recovery in TFP (Figure 4n). Corrado and Mattey (1997) have argued that these plants utilize flexibly operated workstations rather than rigid assembly lines. The typical example that they provide is that of apparel establishments that are a collection of sewing machines doing the same job. This organization of production minimizes interdependence of productive units within the plant as workstations can function rather independently of one another. Thus, large-scale firings of employees would bring little disruption in the remaining operations.

Regarding labor hoarding, it is fair to say that it is practically excluded by construction. It is unlikely that plants forecasted the drop in their profitability (and output) to be temporary creating a strong incentive for labor hoarding. This is evident from the extreme size of employment reductions that they chose. In fact, output and employment remain flat for at least two years after the firings. However, the observations here do not rule out the possibility that labor hoarding may be important in instances of less dramatic adjustment.

During lumpy increases in employment (POSEG), the pattern of TFP is not very pronounced. During the event TFP stays relatively flat while it falls afterwards. It is not clear what lessons one could draw from this except that the hypothesis of internal adjustment costs does not fare so well. A possible interpretation of the evidence is that such costs are

\footnotetext{
${ }^{25}$ See Baily et al. (1996) for a discussion of these costs and evidence that they are important for explaining changes in average labor productivity at the plant level.
} 
asymmetric. This would be puzzling, as one would expect adjustment costs to be heavier for hiring than for firing due to investment needed in specific training. An alternative hypothesis is that internal adjustment costs are symmetric but take effect with a lag in the case of rapid hirings. Without doubt, a structural framework is necessary in order to proceed further.

\section{$7 \quad$ Summary of results}

This paper looked at episodes of dramatic output adjustment by plants. These episodes were classified according to whether the main margin of adjustment was employment (NEGEG and POSEG) or capital (SPIKE). The patterns that emerged were quite interesting. Throughout these episodes there is evidence of both lumpy and smooth changes in employment and capital. In particular, investment spikes seem to be preceded and followed by smooth increases in capital. When plants undertake lumpy changes in production workers' employment this adjustment is completed on average within the course of a year whereas the accompanying adjustment in the employment of non-production workers is spread out over several years.

Independent of the type of adjustment, plants use other margins also. The intensity of materials and energy use is adjusted in anticipation of the lumpy change in capital or employment. Hours per worker and overtime use display temporary changes aimed at facilitating the adjustment in the near term. An interesting observation is that hours per worker and output at the plant level show a non-linear relationship that is not described accurately by a simple statement of positive correlation between them. The workquarter of capital is adjusted to provide the desired change in capital services. This is reversed after a SPIKE but not after a POSEG or NEGEG event reflecting the fact that during the latter two episodes many plants change their shift behavior. The capital workquarter and, in particular, the shift margins are utilized by variable workquarter plants more than by continuous processors. ${ }^{26}$ The results suggest that variations in the energy- or materialscapital ratio may not proxy well for variations in the capital workquarter, even for variable workquarter plants.

\footnotetext{
${ }^{26}$ Mattey and Strongin (1995) also document this fact extensively.
} 
Plants vary the utilization of their productive capacity quite substantially during these adjustment episodes. In employment adjustments capacity utilization is positively correlated with plant output. However, during expansions of output that are associated with investment spikes capacity utilization falls.

The dynamic behavior of plant productivity is very interesting. It provides some evidence of learning effects associated with the introduction of new technology as a result of a SPIKE. Additionally, there seems to be some evidence of productivity costs to rapid employment adjustment. Both of these findings point to the importance of organizational structure and the interdependence of capital and labor input decisions in understanding the costs of adjustment. They also demonstrate that plant-level productivity is to a large extent endogenous. Thus, finding appropriate instruments for the econometric estimation of production relationships at the plant level is particularly tricky. In general, the finding of a positive simple correlation between productivity and output in aggregate data is not observed at the plant level during episodes of lumpy adjustment.

The empirical approach that I employ in this first look at the data is descriptive and non-parametric rather than structural. This seems to be the best way to take a first look at these dynamic relationships during plant adjustment. There is no doubt that the estimation of a structural model that specifies the nature of shocks buffeting plants and the nature of costs to adjusting different margins is the right pathto follow from here. 


\section{REFERENCES}

Baily, Martin N.; Bartelsman, Eric J. and Haltiwanger, John. "Labor Productivity: Structural Change and Cyclical Dynamics." NBER Working Paper 5503, March 1996.

Basu, Susanto. "Capital Utilization and Returns to Scale: Comment." NBER Macroeconomics Annual, 1995, pp. 110-117.

Basu, Susanto, and Fernald, John. "Returns to Scale in U.S. Production: Estimates and Implications." Journal of Political Economy, April 1997, 105(2), pp. 249-83.

Bresnahan, Timothy F. and Ramey, Valerie A. "Output Fluctuations at the Plant Level." Quarterly Journal of Economics, 1994, 109(3), pp. 593-624.

Burnside, Craig; Eichenbaum, Martin and Rebelo, Sergio. "Capital Utilization and Returns to Scale." NBER Macroeconomics Annual, 1995, pp. 67-109.

Caballero, Ricardo J.; Engel, Eduardo M. R. A. and Haltiwanger, John. "Aggregate Employment Dynamics: Building from Microeconomic Evidence." American Economic Review, January 1997, 87(1), pp. 115-37.

Cooper, Russell; Haltiwanger, John and Power, Laura. "Machine Replacement and the Business Cycle: Lumps and Bumps." Mimeo, NBER WP 5260, 1995.

Corrado, Carol and Mattey, Joe. "Capacity Utilization." Journal of Economic Perspectives, Winter 1997, 11(1), pp. 151-67.

Doms, Mark and Dunne, Timothy. "Capital Adjustment Patterns in Manufacturing Plants." Review of Economic Dynamics, 1998, 1, pp.409-29.

Greenwood, Jeremy and Jovanovic, Boyan. "Accounting for Growth." Mimeo, Rochester University, June 1998.

Jorgenson, Dale, and Griliches, Zvi. "The Explanation of Productivity Change." Review of Economic Studies, 1967, 34, pp. 249-283.

Hamermesh, Daniel S. "Labor Demand and the Structure of Adjustment Costs." American Economic Review, September 1989, 79(4), pp. 674-89. 
Hamermesh, Daniel S. and Pfann, Gerard S. "Adjustment Costs in Factor Demand." Journal of Economic Literature, September 1996.

Mattey, Joe and Strongin, Steve. "Factor Utilization and Margins for Adjusting Output: Evidence from Manufacturing Plants." Mimeo, Federal Reserve Board, WP 95-12, March 1995.

Power, Laura. "The Missing Link: Technology, Investment, and Productivity." The Review of Economics and Statistics, 1998, pp. 300-313.

Shapiro, Matthew D. "Capital Utilization and Capital Accumulation: Theory and Evidence." Journal of Applied Econometrics, July 1986, 1(3), pp. 211-234. 


\section{APPENDIX}

This Appendix contains the definitions of the variables used in the analysis.

Capacity: Plant operations at capacity are termed in the Survey of Plant Capacity as "Preferred level of operations." The exact definition follows.

"The preferred level of operations is an intermediate level of operations between actual operations and practical capacity that you would prefer not to exceed because of costs or other considerations. Implicit in the idea of a preferred level of operations is the theory that there is a preferred level of operations at which profits are maximized. This is a level where marginal revenue equals marginal costs. The preferred level should not exceed practical capacity."

"Practical capacity is the greatest level of output this plant can achieve within the framework of a realistic work pattern, a normal product mix, and the schedule, machinery, and equipment already in place and ready to operate."

I use the preferred definition as it corresponds quite closely to economic concepts of capacity that incorporate cost considerations. The practical definition, on the other hand, seems closer to an engineering notion of capacity best described as "running the machines all out."

Capacity utilization: Actual production/preferred production.

State of Demand: The state of plant operations described in terms of actual shifts $\left(S^{A}\right)$ and preferred capacity shifts $\left(S^{C}\right)$ worked per day.

State $=1$ if $S^{A}=1$ and $S^{C}=1$

State $=2$ if $S^{A}=1$ and $S^{C}=2$ or 3

State $=3$ if $S^{A}=2$ and $S^{C}=1$

State $=4$ if $S^{A}=2$ and $S^{C}=2$

State $=5$ if $S^{A}=2$ and $S^{C}=3$

State $=6$ if $S^{A}=3$ and $S^{C}=1$ or 2

State $=7$ if $S^{A}=3$ and $S^{C}=3$.

Workquarter of capital: The hours worked per day times the days worked per week times the weeks worked per quarter.

Change in workquarter due to shift changes: It is calculated by holding the number of 
days per week constant while allowing shifts per day to take their actual values.

Output: (Total value of shipments + Change in work in progress inventory + Change in finished goods inventory)/(shipments deflator).

Labor productivity (log): $\log (($ Total value of shipments + Change in work in progress inventory + Change in finished goods inventory)/shipments deflator)- log(production worker hours+non-production worker hours). Non-production worker hours are computed by multiplying the plant's non-production workers by the average annual hours of non-production workers in the corresponding two-digit industry.

Total factor productivity (log): output - $\mathrm{a}^{*}\left(\right.$ total hours) - $\mathrm{b}^{*}$ (real capital stock in equipment) - $\mathrm{c}^{*}$ (real capital stock in structures) - $\mathrm{d}^{*}$ (cost of fuels + cost of contract work + cost of materials and parts+cost of purchased electricity). The above variables are in logs and deflated using corresponding 4-digit industry deflators. Factor elasticities are measured via average 4-digit industry cost shares. Industry data are taken from the NBER-CES Manufacturing Productivity Database. The cost shares for labor input assume a $17 \%$ supplementary cost over actual wages (this is the mean excess of total employment compensation to wages and salaries in the NIPA series for manufacturing between 1972-87). The capital share is calculated using 2-digit BLS rental rates.

Total factor productivity adjusted for utilization (log): $\log (\mathrm{TFP})-\mathrm{b}^{*}$ (workquarter of capital).

Capital Stock: Total stock of structures and equipment at the beginning of the period. The two stocks were calculated separately using a perpetual-inventory method and then aggregated. Nominal gross investment was deflated using 4-digit SIC investment deflators. BEA depreciation rates were applied at the 2-digit SIC level. In 1972 the capital stock was initialized to gross book values of equipment and structures deflated by the ratio of 2-digit industry real net capital stock to industry nominal gross capital stock (available from the BEA).

\section{TECHNOLOGY CLASS:}

Continuous Processors are industries in which the average workquarter at capacity exceeds 2000 hours per quarter.

Variable Workquarter industries are those in which the average coefficient of variation $(\mathrm{CV})$ of the workquarter exceeds the median $\mathrm{CV}$, unless the industry is already classified 
as a continuous processor ( $\mathrm{CV}=$ standard deviation of actual workquarter/mean actual workquarter, at the plant level).

Other industries include those not already classified as continuous processing or variable workquarter.

According to Murray Foss, the following three-digit industries are classified as continuous processors: 261-63; 28, except 283-85, 89; 29; and 331, 333. Foss includes 10 industries as continuous processors that we do not $(2875,2879,2951,2952,2992,2999,3315,3316$, 3317, and 3333). Conversely, we include 16 industries as continuous processors that Foss does not (2046, 2063, 2075, 2083, 2492, 2646, 2661, 2895, 3221, 3229, 3241, 3274, 3275, 3296, 3353, and 3355). See Foss, Murray F. "Changing Utilization of Fixed Capital: An Element in Long-Term Growth." Washington: American Enterprise Institute. 1984. 
FIGURE 1: INVESTMENT SPIKE (MATCHED SAMPLE)

\section{Frequency of Technology Class}

Event Population Total Population

$\begin{array}{lrrrr}\text { Continuous Processors } & 446 & 22.1 \% & 2,611 & 27.8 \% \\ \text { Variable Workquarter } & 980 & 48.6 \% & 4,127 & 44.0 \% \\ \text { Other } & 589 & 29.2 \% & 2,639 & 28.1 \%\end{array}$
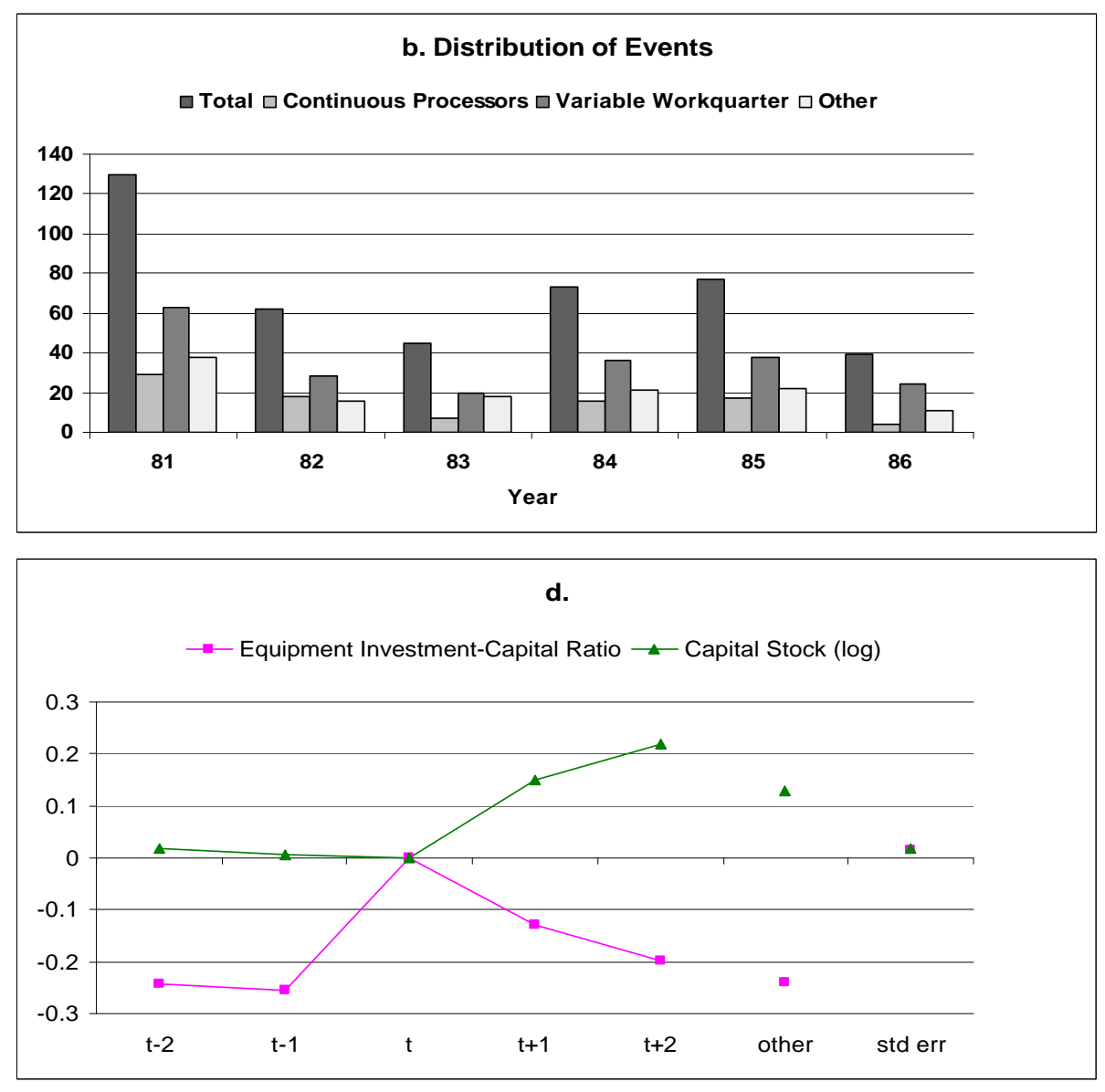
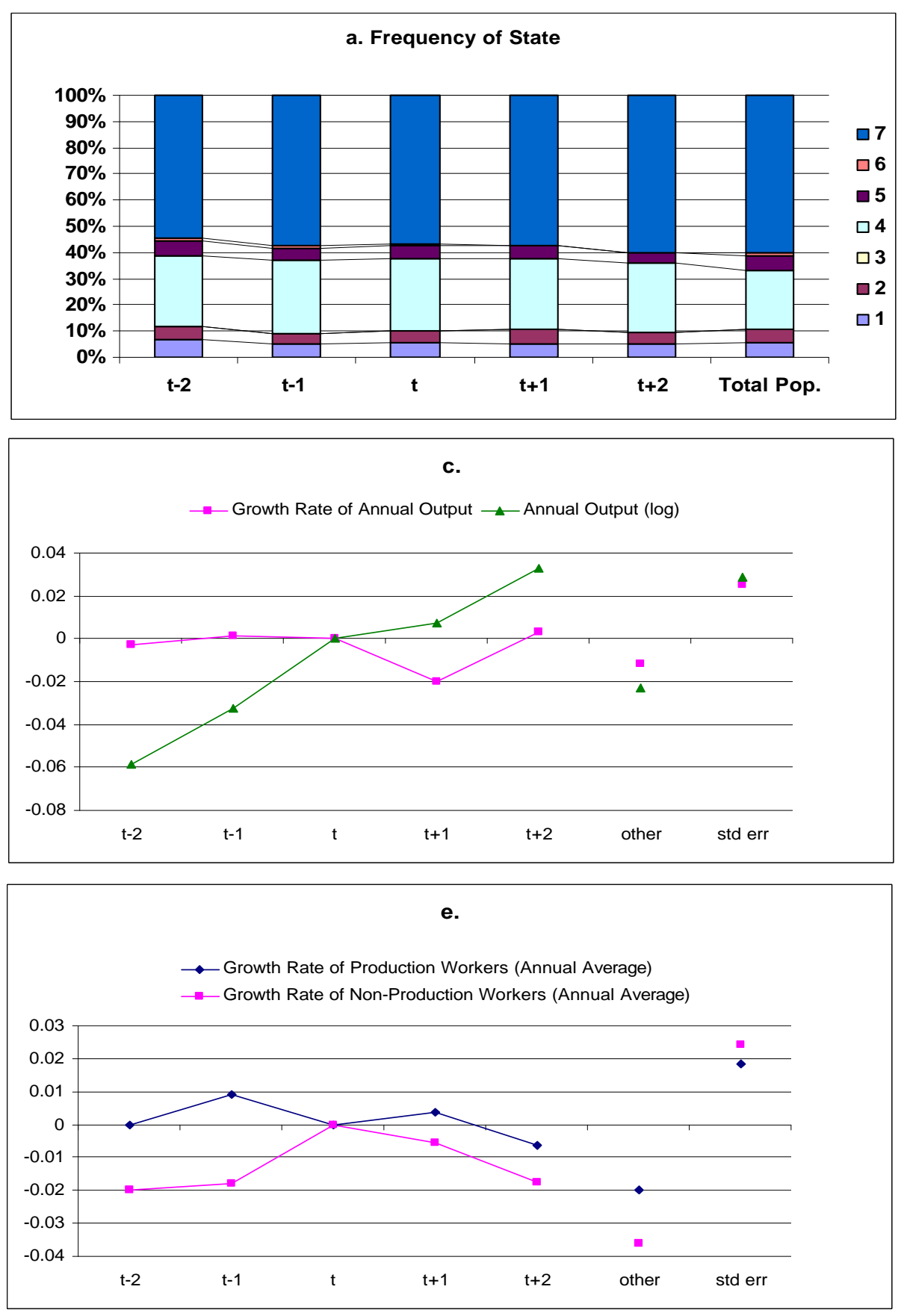

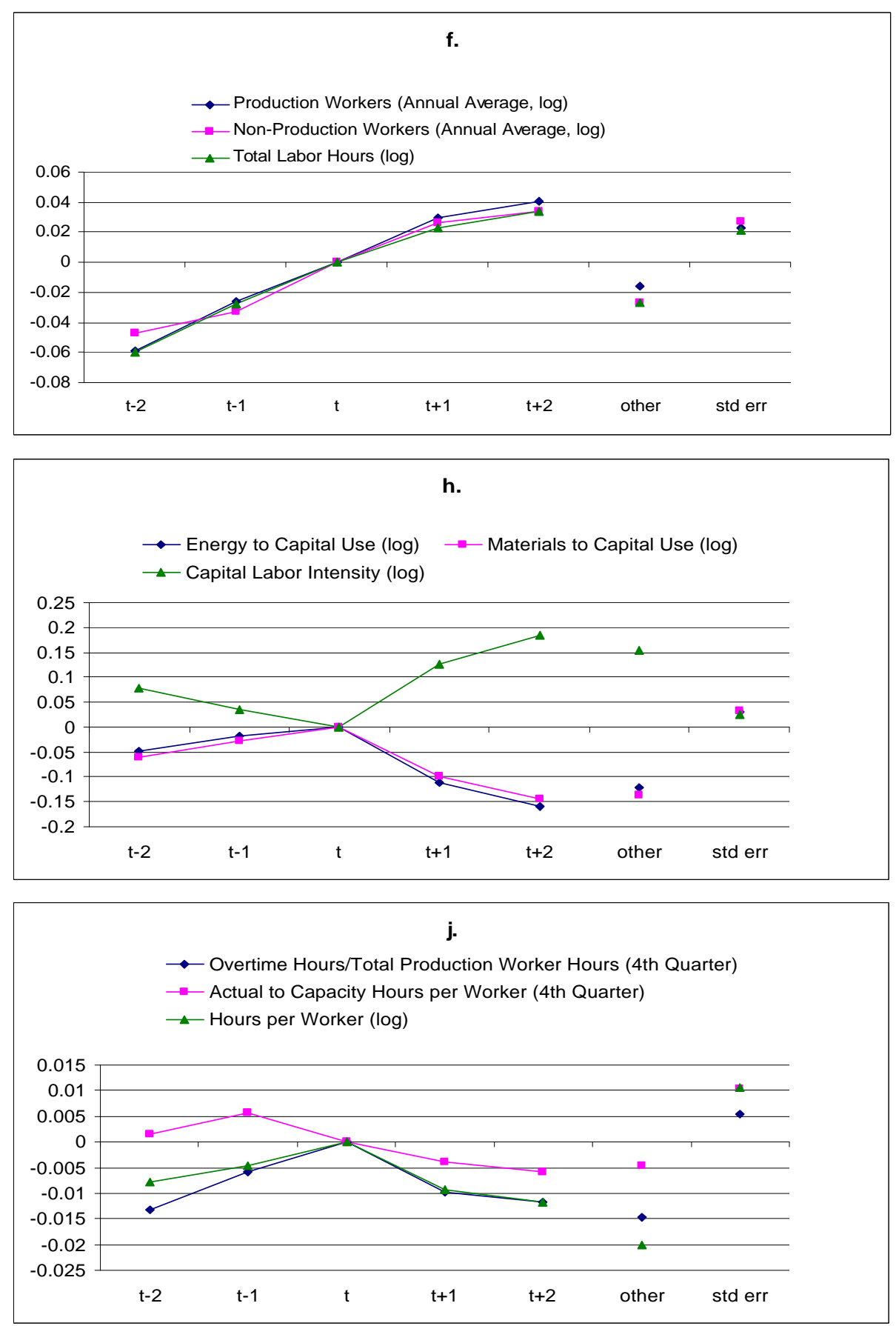

g.

- Skilled Workers' Share of Employment (log) - - Skilled Workers' Share of Wages (log)

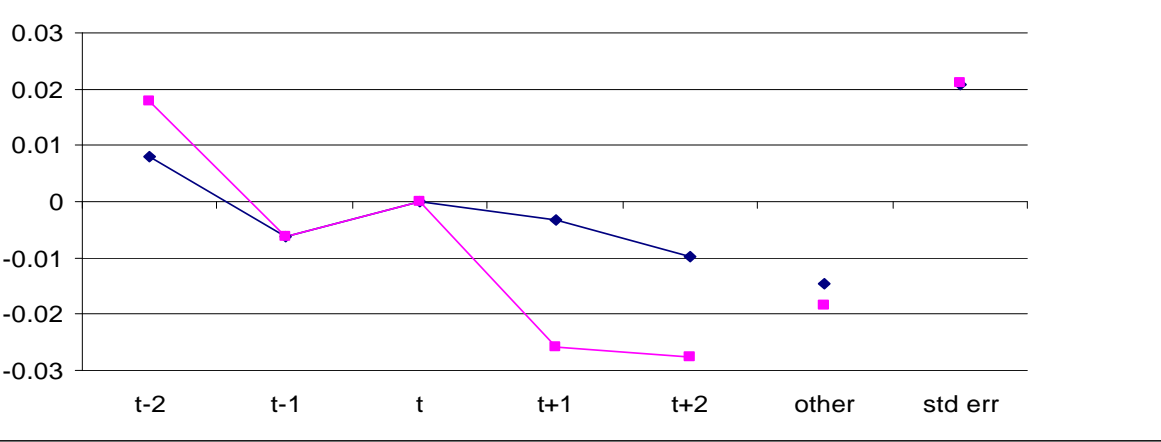

i.

$\rightarrow-$ Energy to Capital Services Use (log) $\rightarrow-$ Materials to Capital Services Use (log)

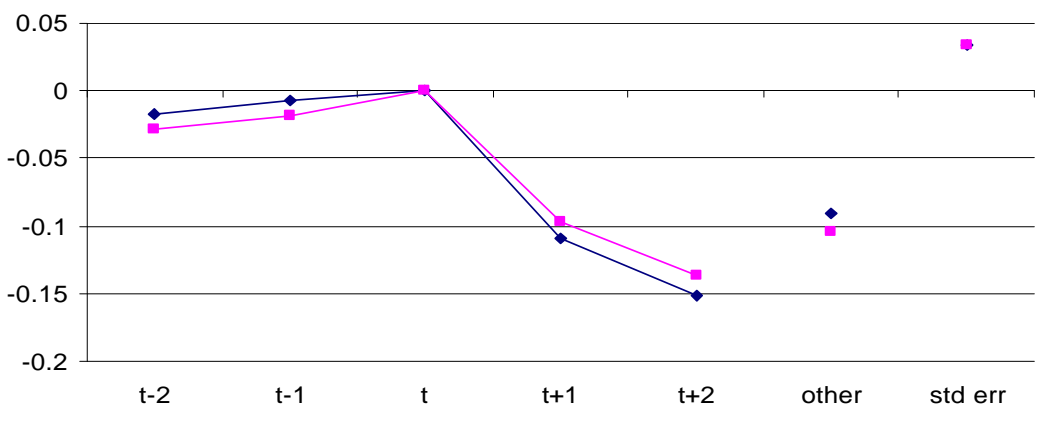

k.

- Workquarter of Capital (Annual Average, log) $\_$Actual to Capacity Workquarter (Annual Average)

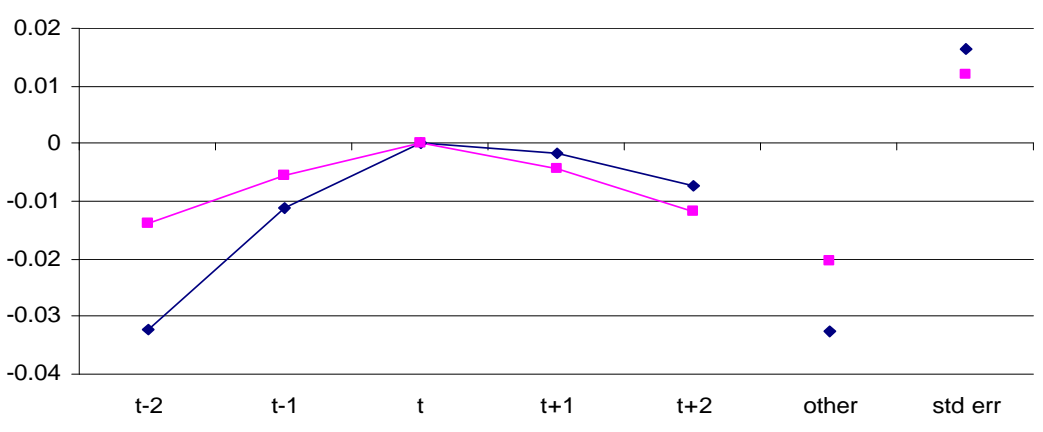




\section{FIGURE 1: INVESTMENT SPIKE (MATCHED SAMPLE)}

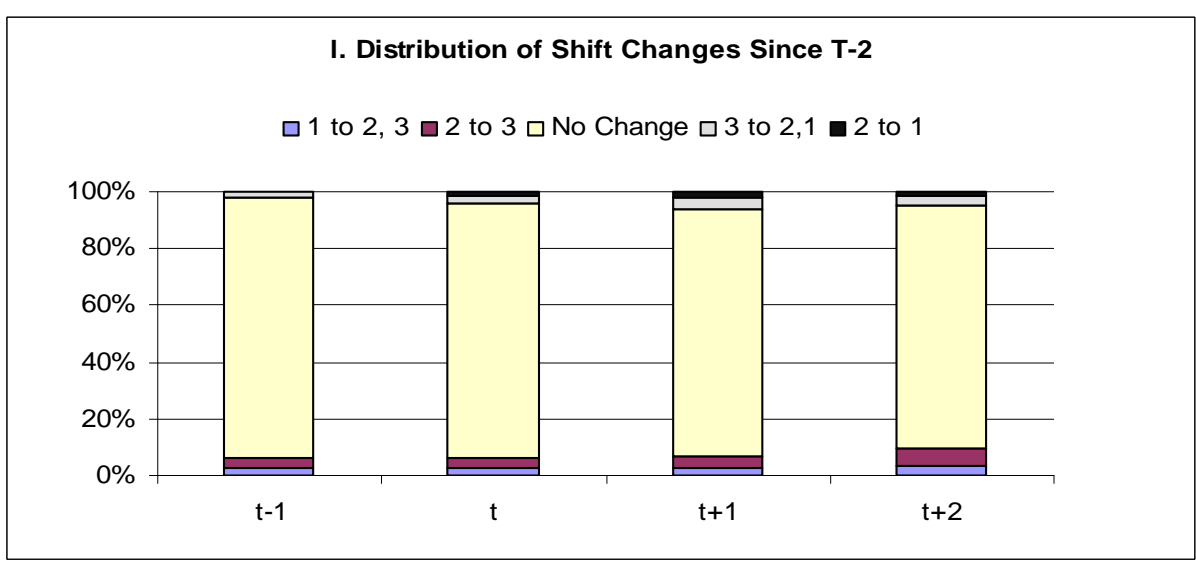

n.
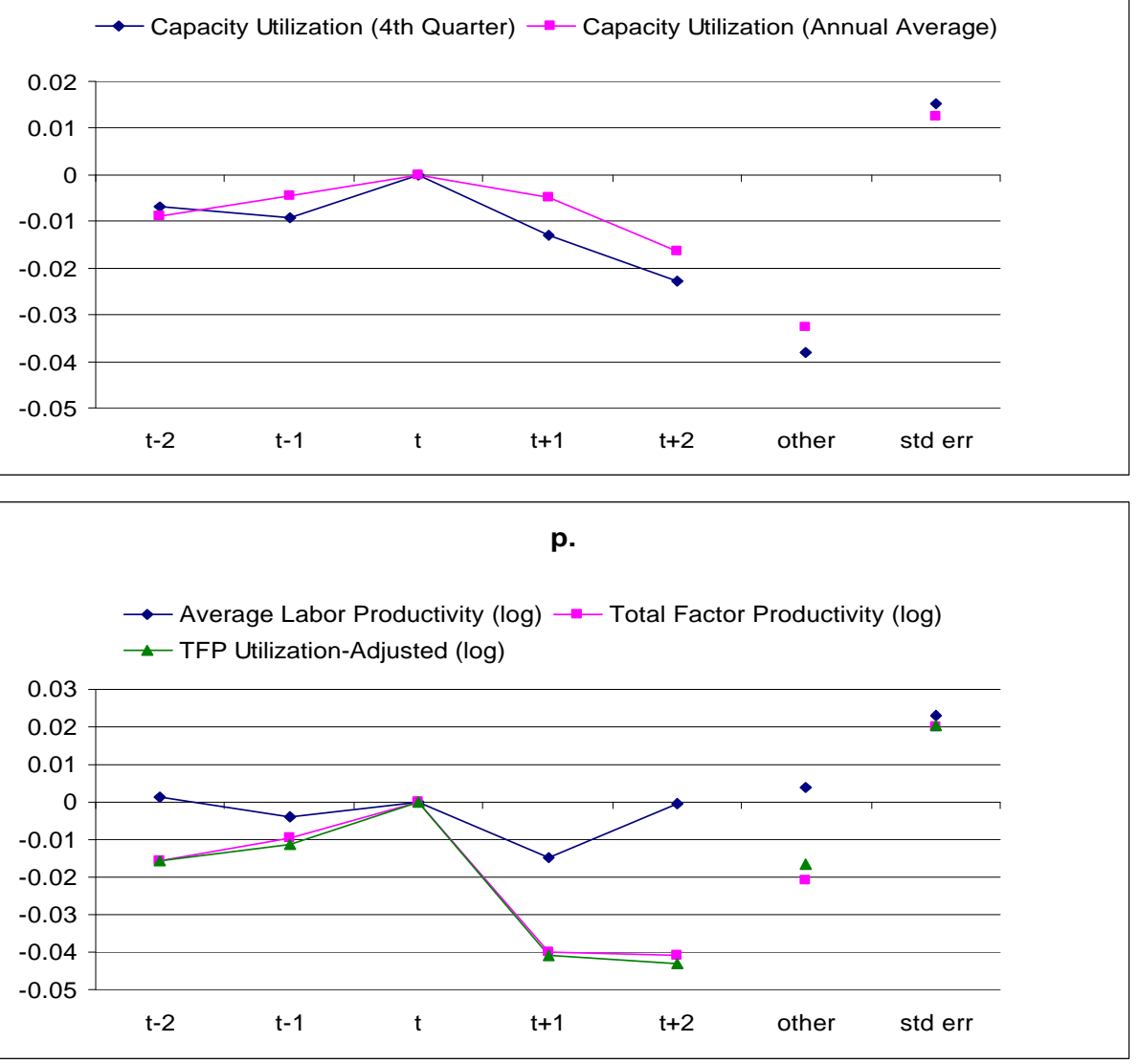

m. Share of Change in Workquarter Due to Shift Changes

- Total $\rightarrow$ Continuous Processors $\triangle$ Variable Workquarter $\rightarrow$ Other

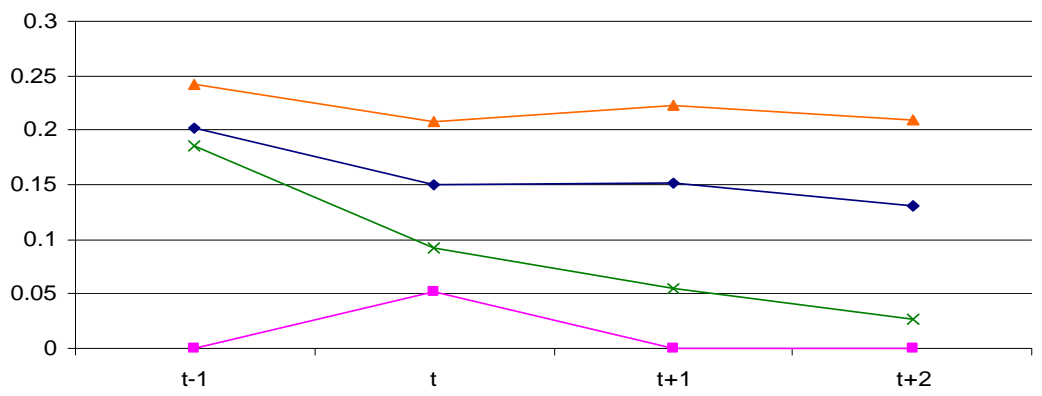

o.
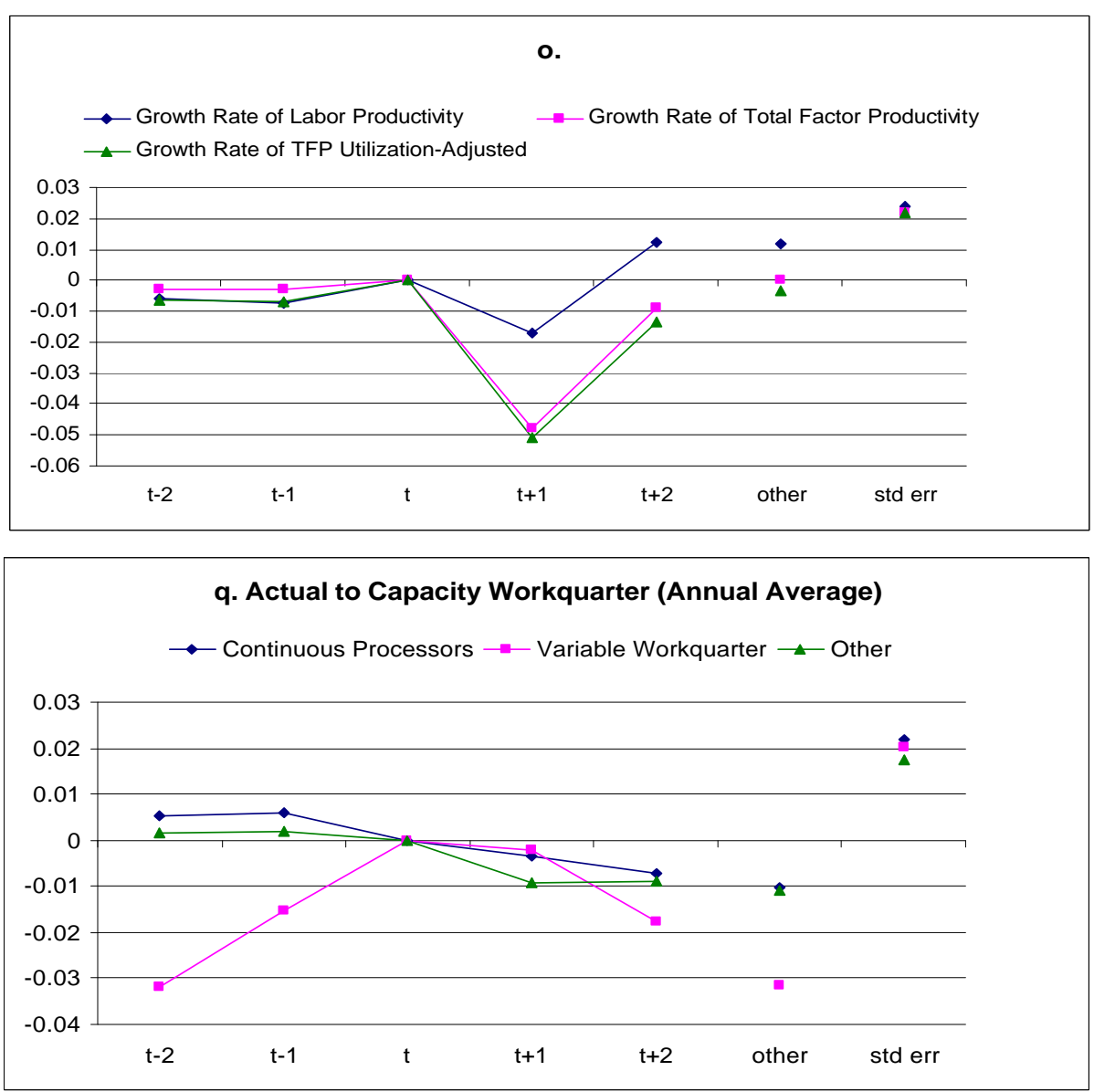
FIGURE 1: INVESTMENT SPIKE (MATCHED SAMPLE)
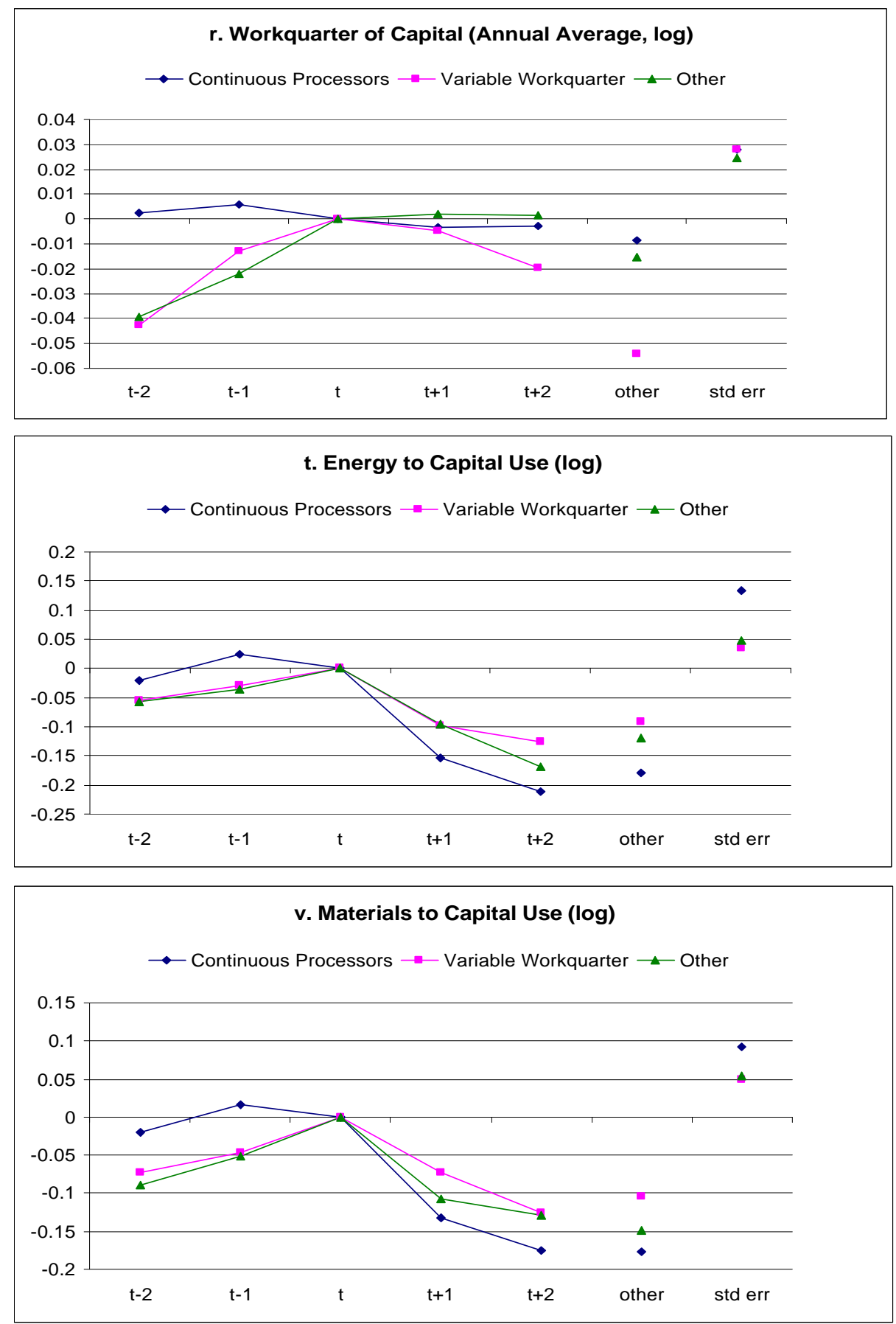
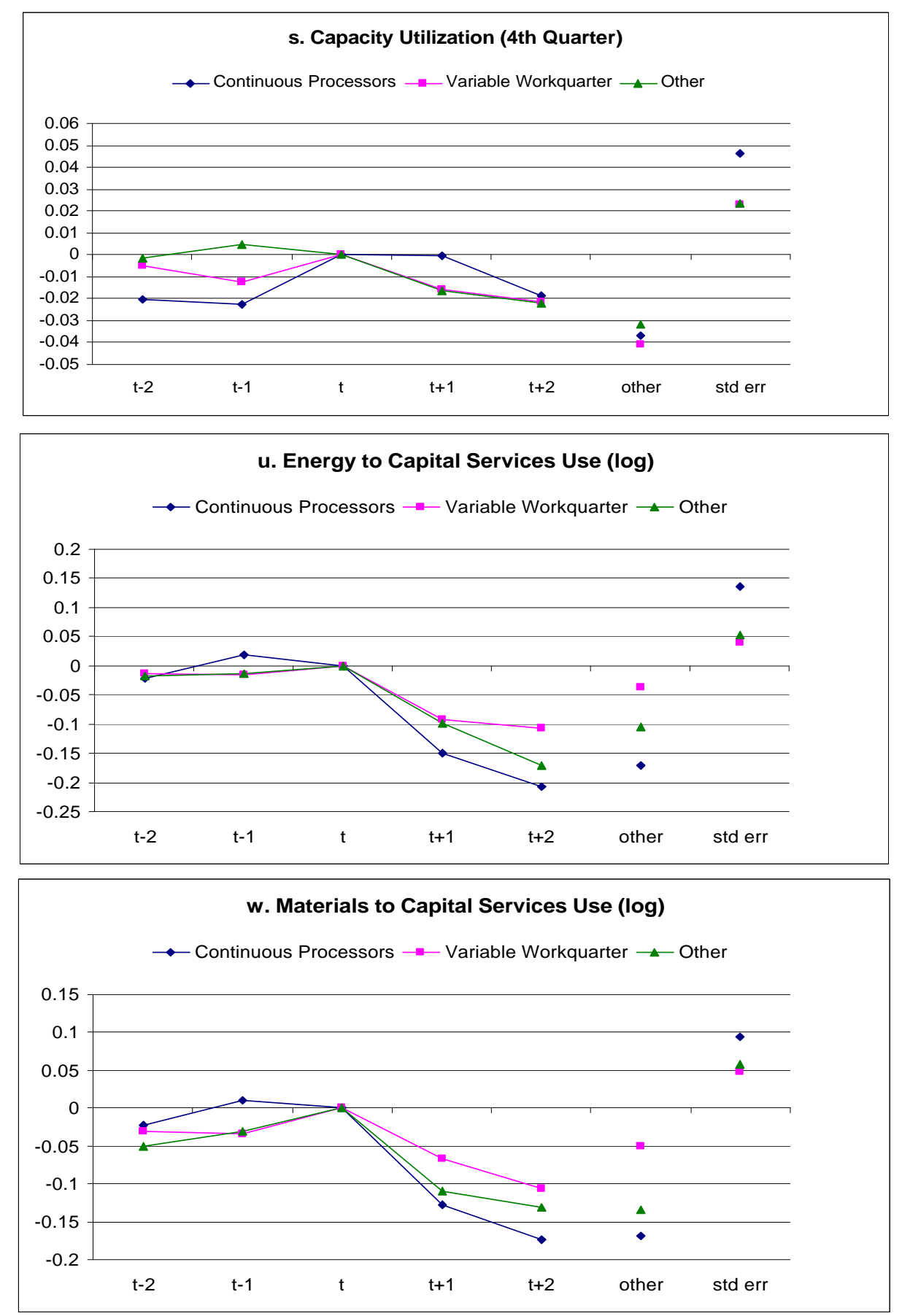
FIGURE 2: INVESTMENT SPIKE (BALANCED-LRD SAMPLE)

\section{Frequency of Technology Class}

\begin{tabular}{lrrrr} 
& \multicolumn{2}{c}{ Event Population } & \multicolumn{2}{c}{ Total Population } \\
Continuous Processors & 8,432 & $11.0 \%$ & 24,923 & $13.5 \%$ \\
Variable Workquarter & 33,985 & $44.2 \%$ & 82,842 & $44.8 \%$ \\
Other & 34,411 & $44.8 \%$ & 77,151 & $41.7 \%$
\end{tabular}

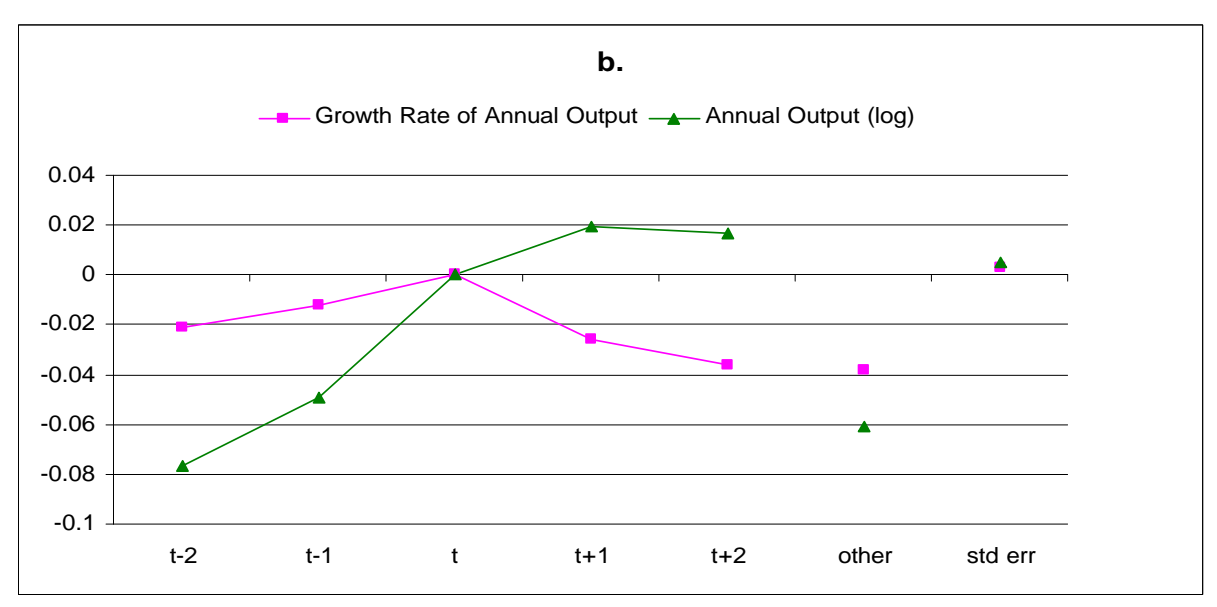

d.

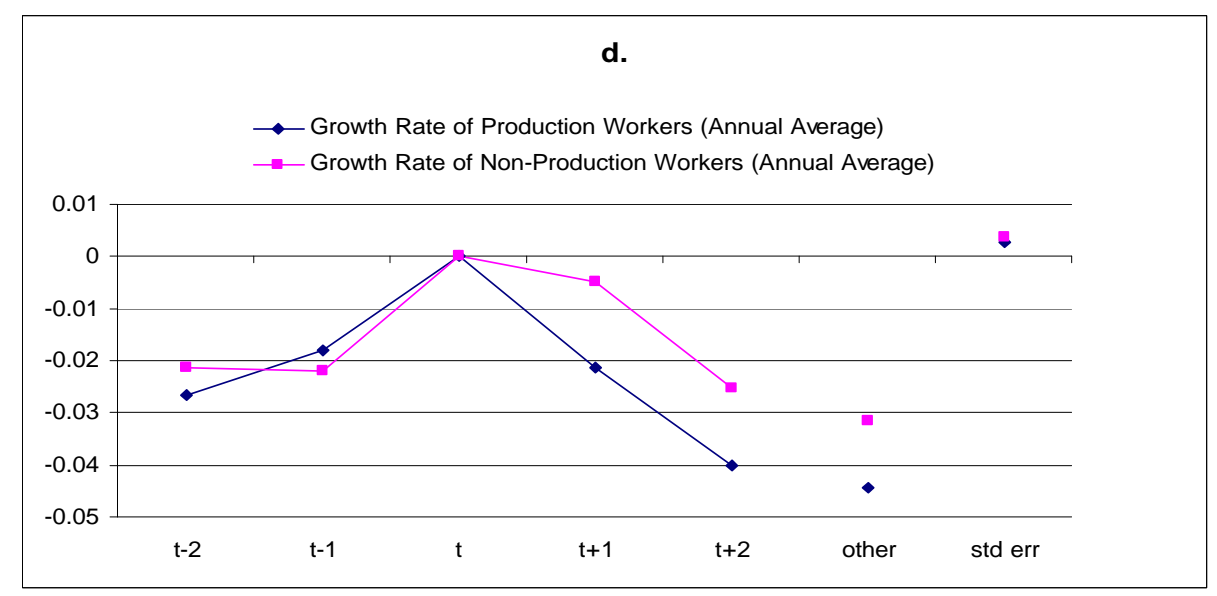

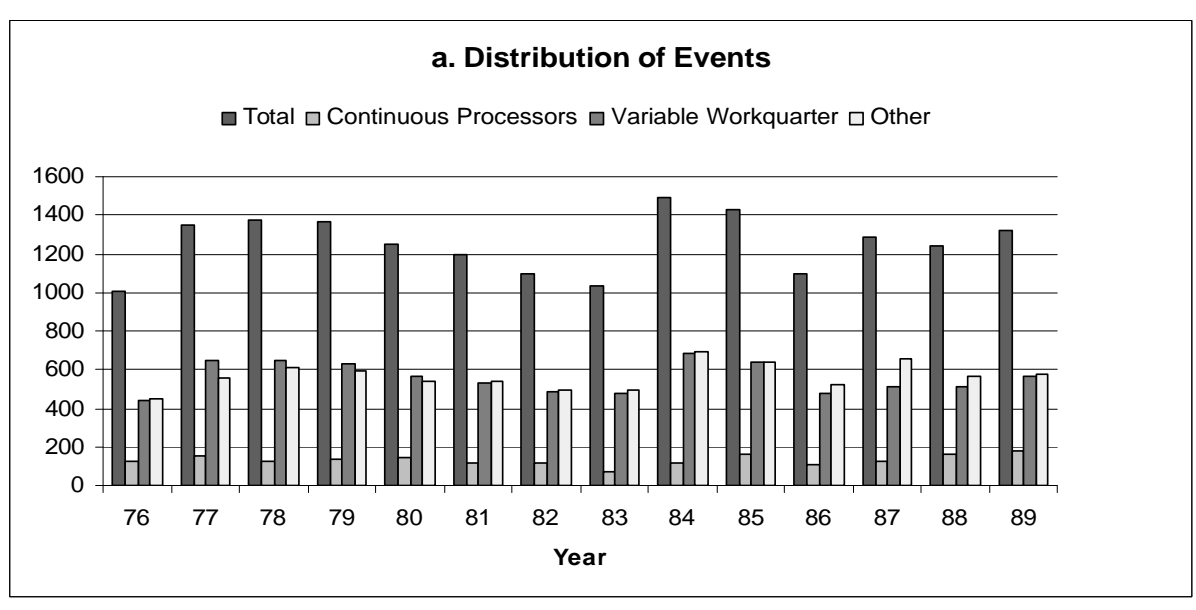

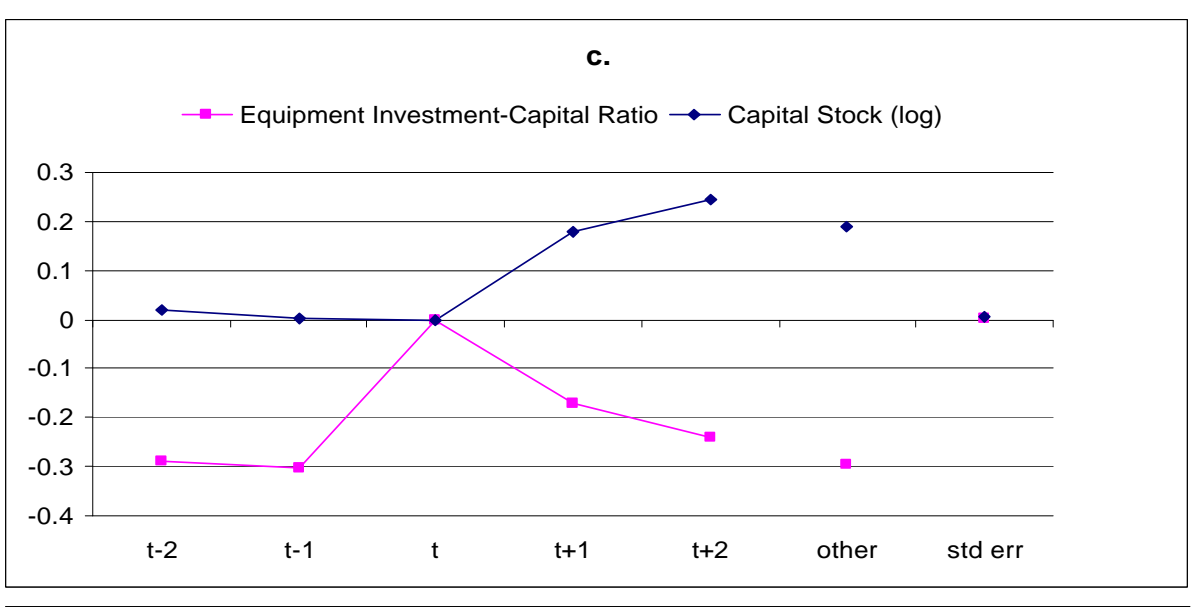

e.

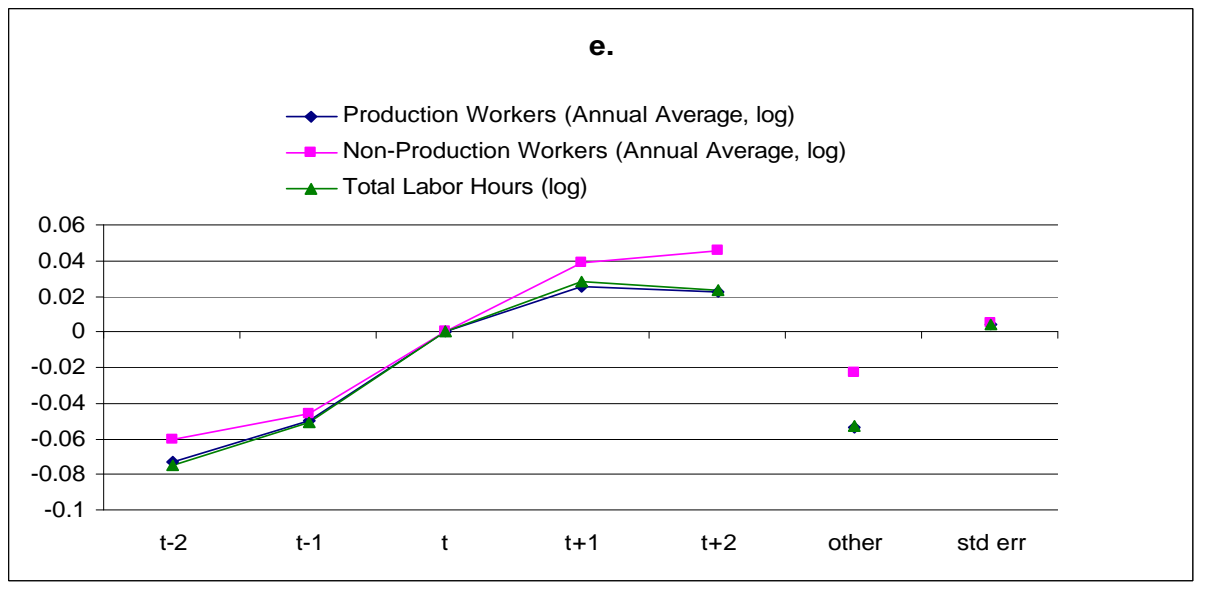




\section{FIGURE 2: INVESTMENT SPIKE (BALANCED-LRD SAMPLE)}
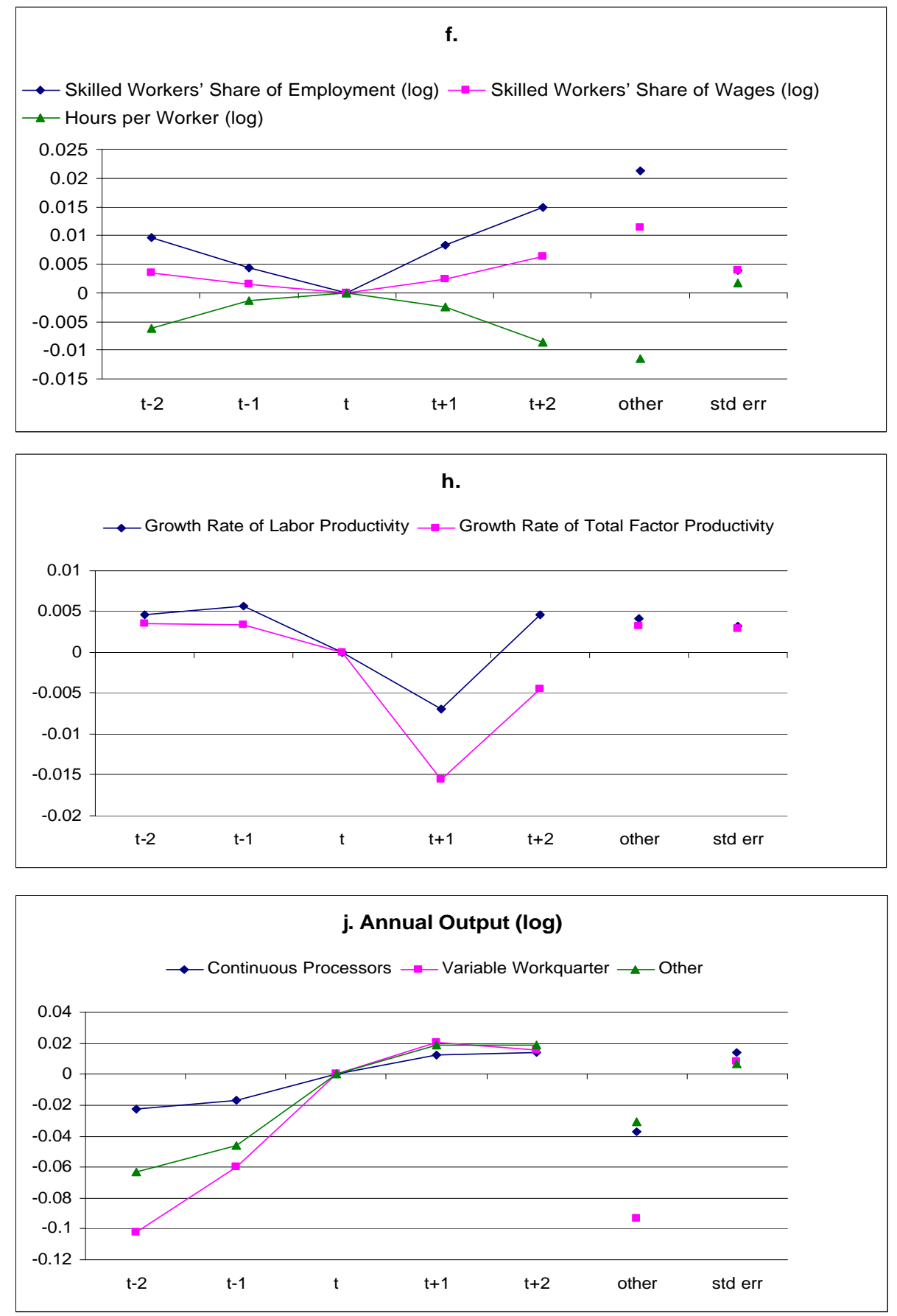
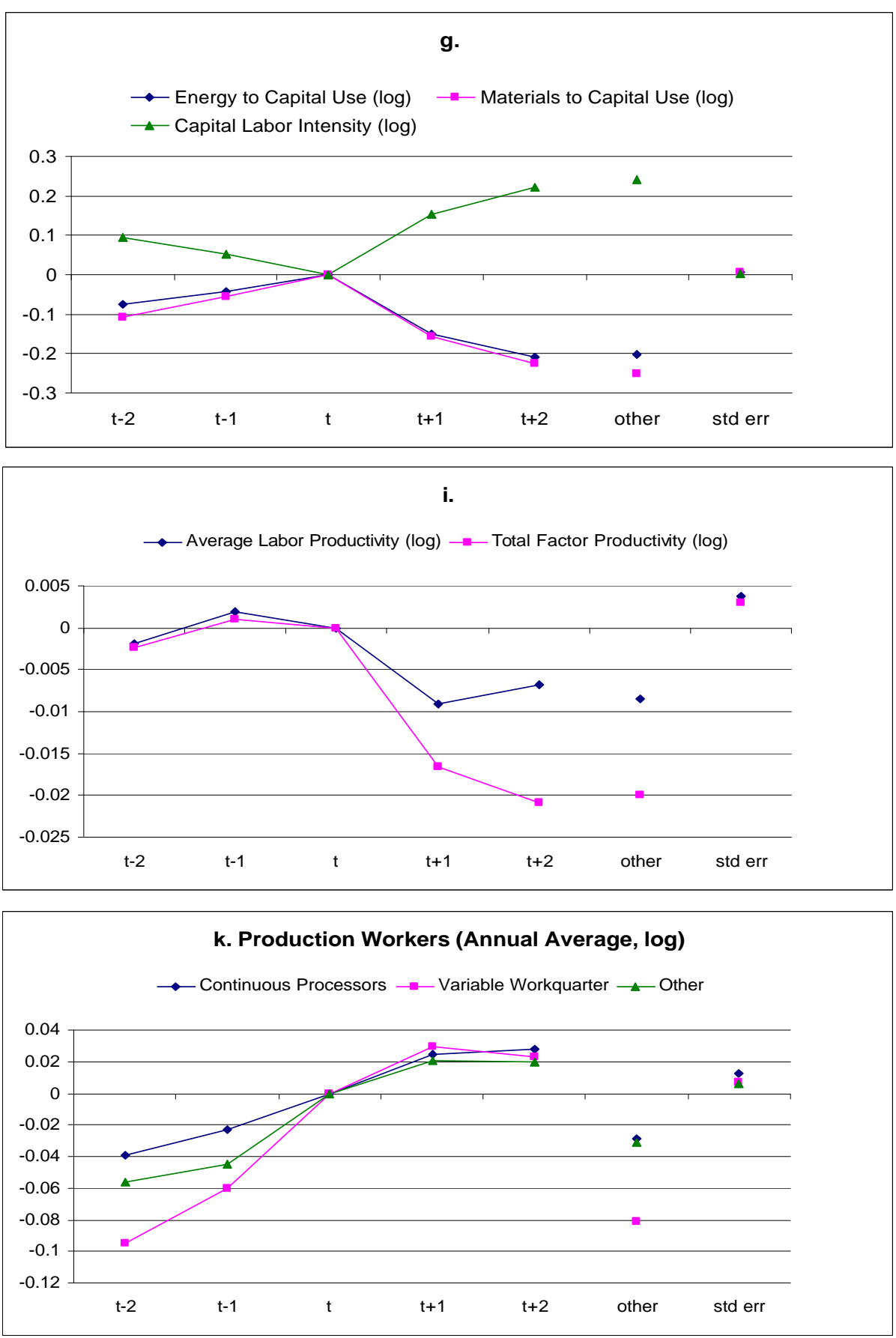
FIGURE 2: INVESTMENT SPIKE (BALANCED-LRD SAMPLE)
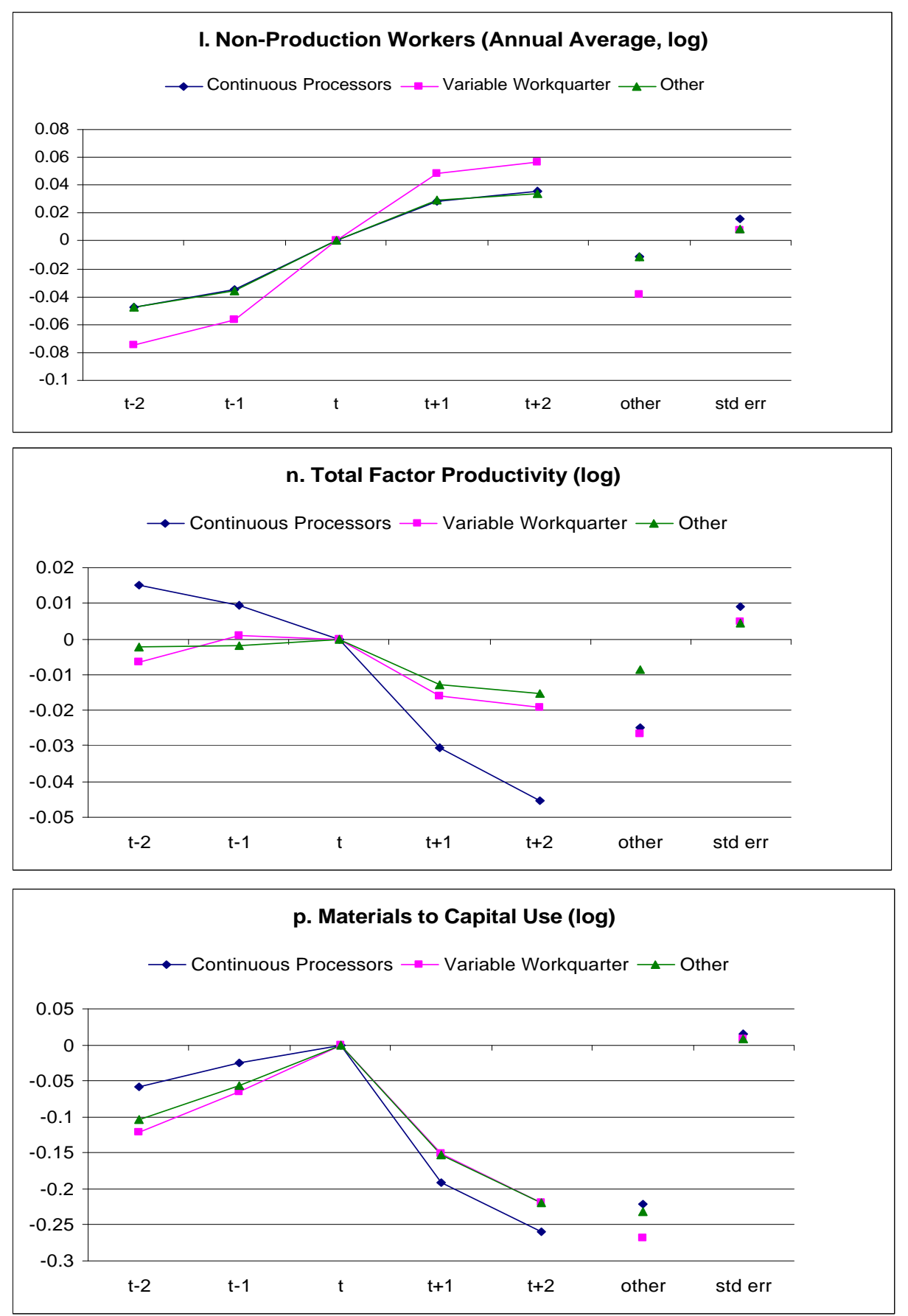

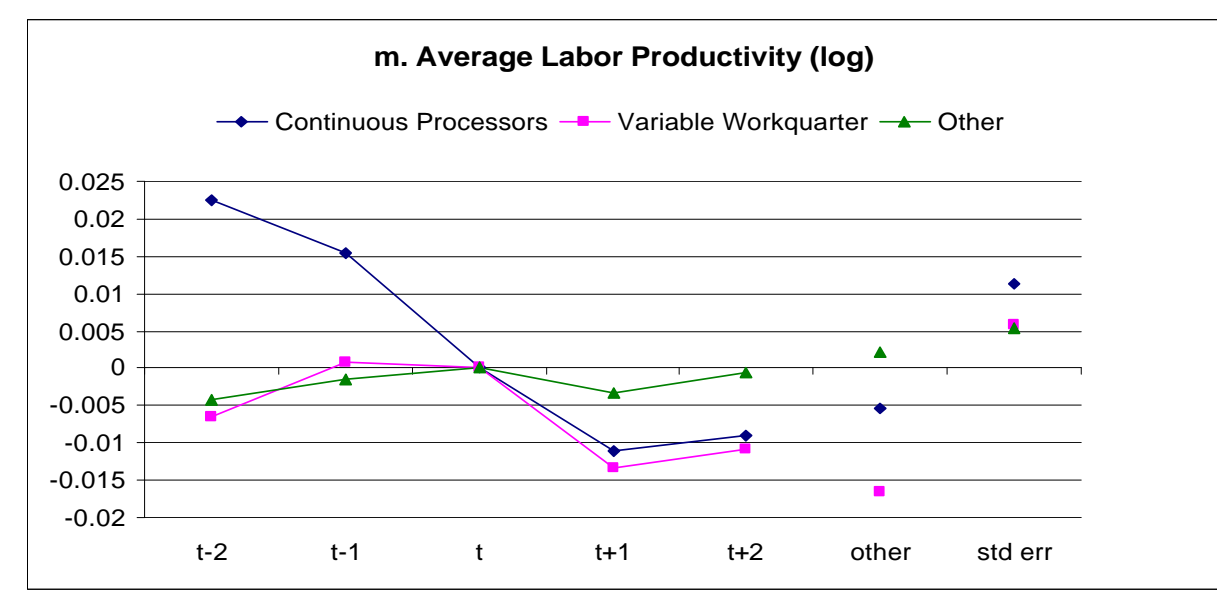

o. Energy to Capital Use (log)

- Continuous Processors - Variable Workquarter $\_$Other
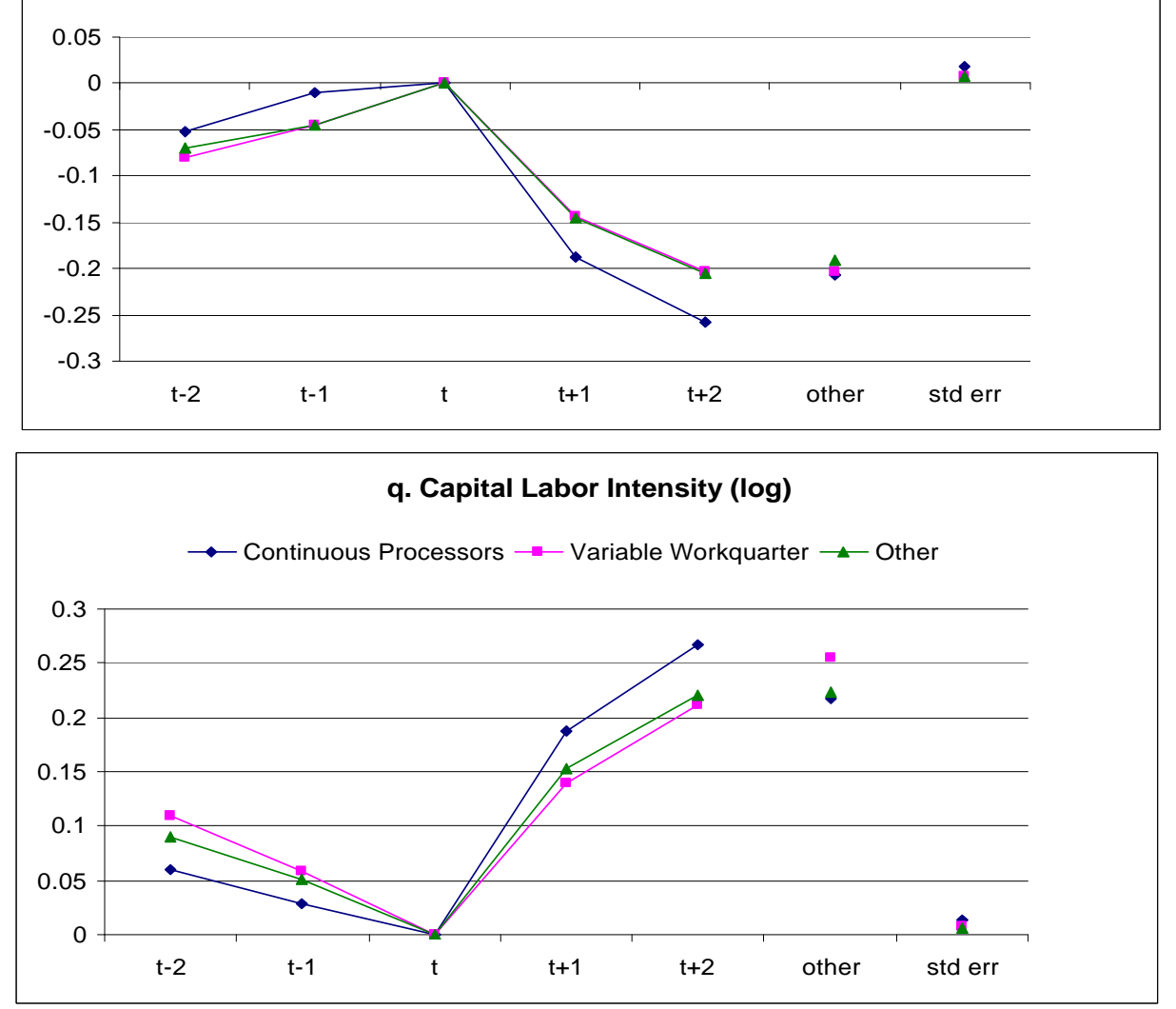
FIGURE 3: NEGATIVE EMPLOYMENT GROWTH (MATCHED SAMPLE)

\section{Frequency of Technology Class}

\begin{tabular}{lrrrr} 
& Event Population & \multicolumn{2}{c}{ Total Population } \\
Continuous Processors & 570 & $28.4 \%$ & 2,611 & $27.8 \%$ \\
Variable Workquarter & 924 & $46.0 \%$ & 4,127 & $44.0 \%$ \\
Other & 513 & $25.6 \%$ & 2,639 & $28.1 \%$
\end{tabular}
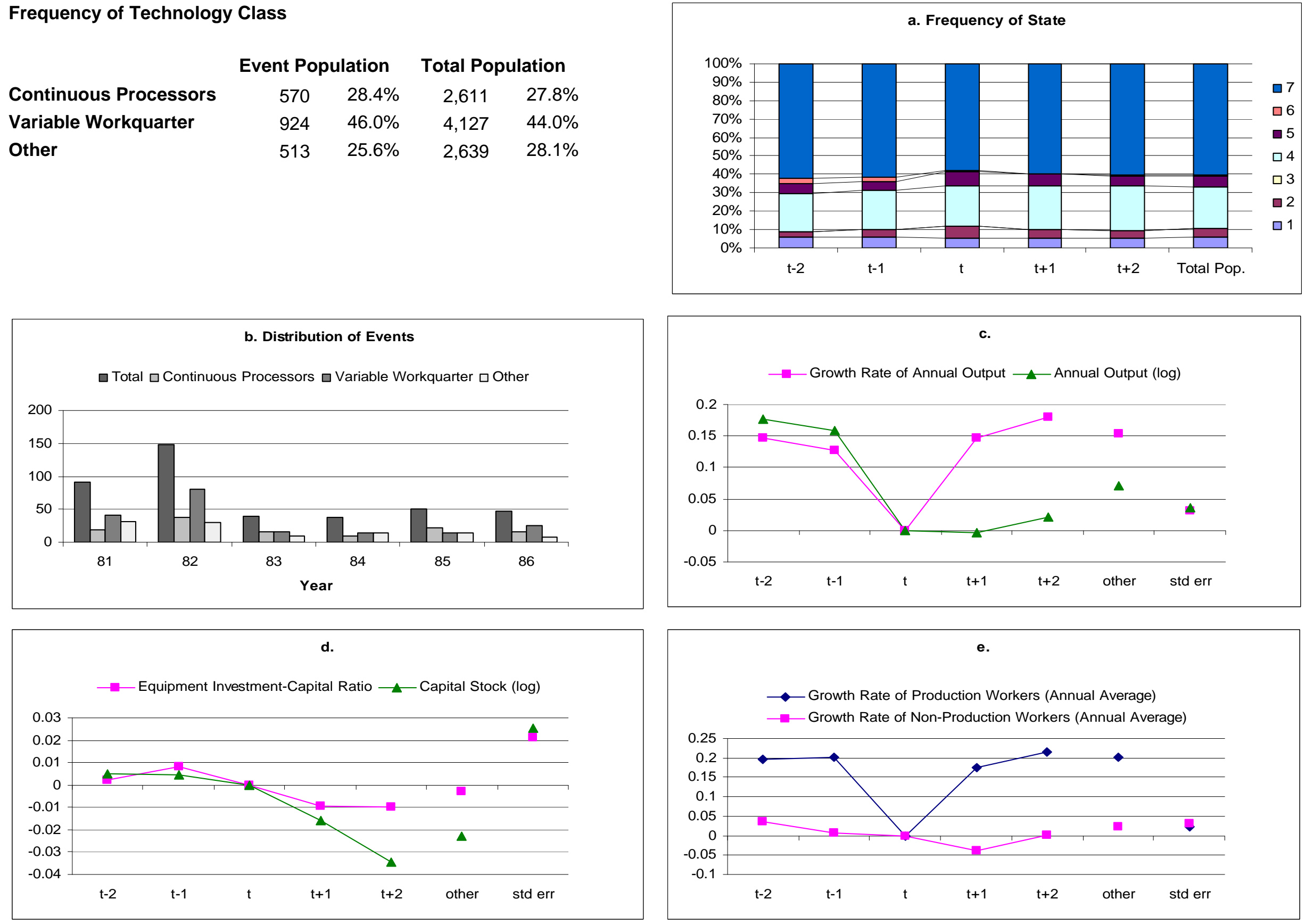
FIGURE 3: NEGATIVE EMPLOYMENT GROWTH (MATCHED SAMPLE)
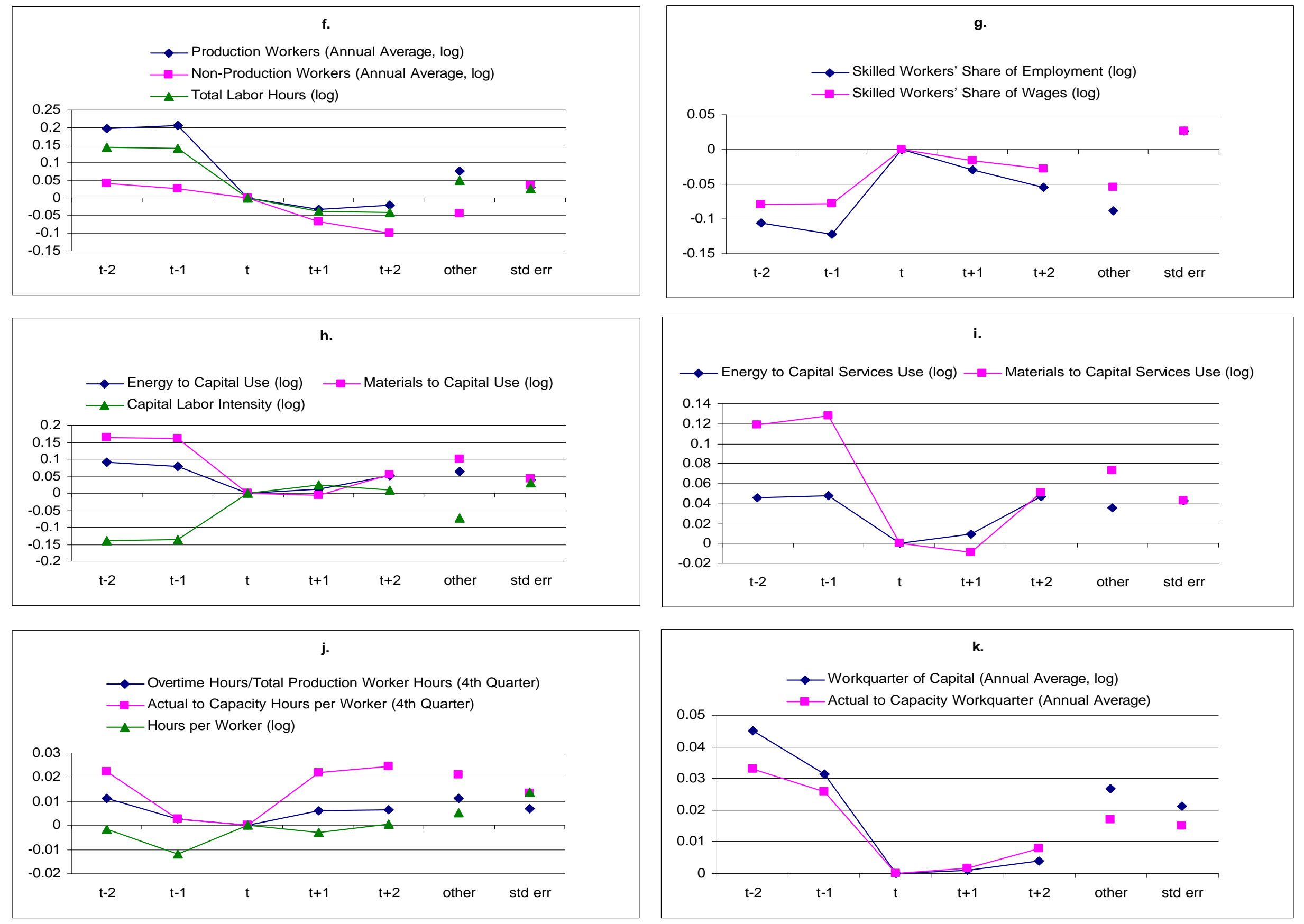


\section{FIGURE 3: NEGATIVE EMPLOYMENT GROWTH (MATCHED SAMPLE)}
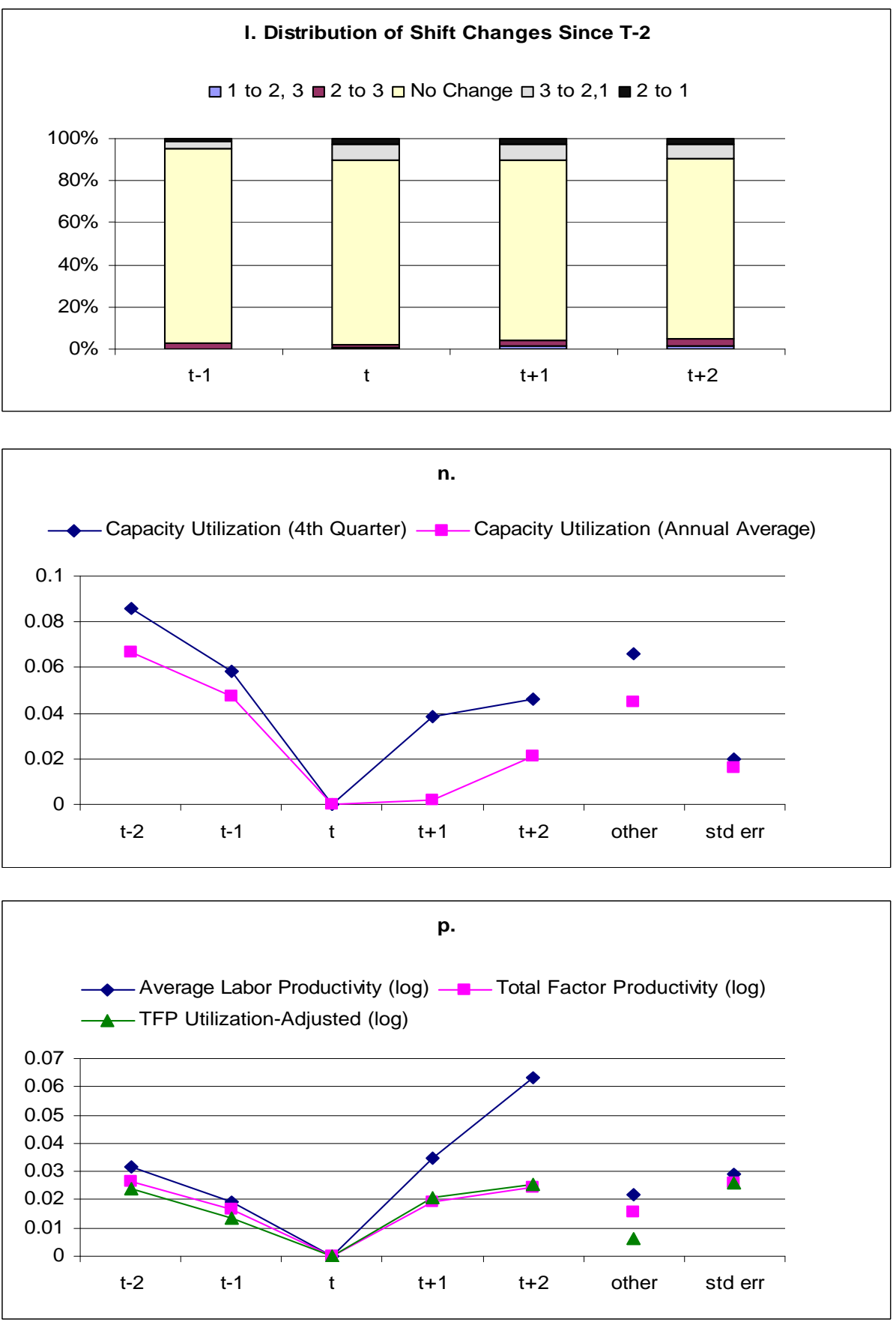

m. Share of Change in Workquarter Due to Shift Changes
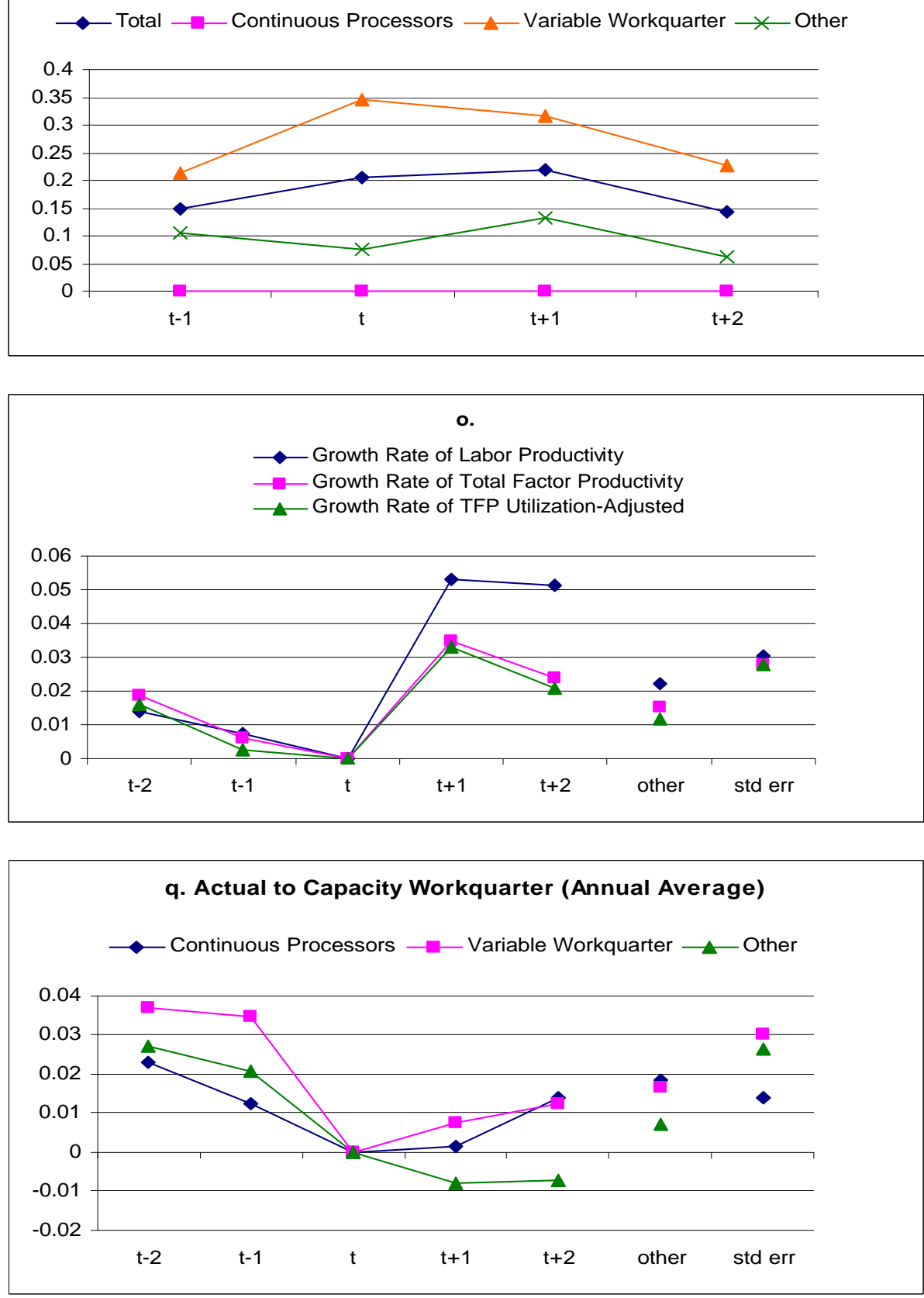

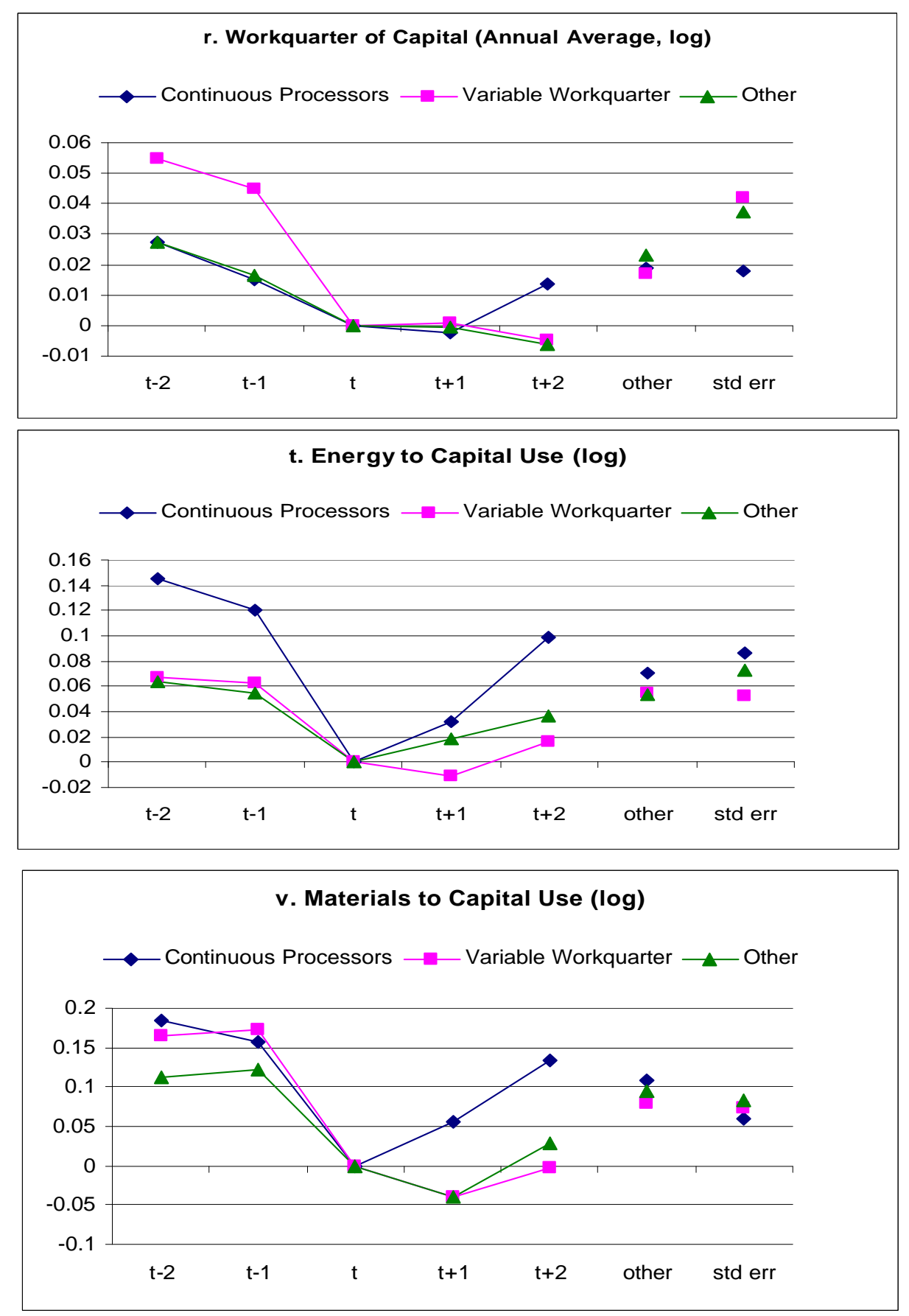
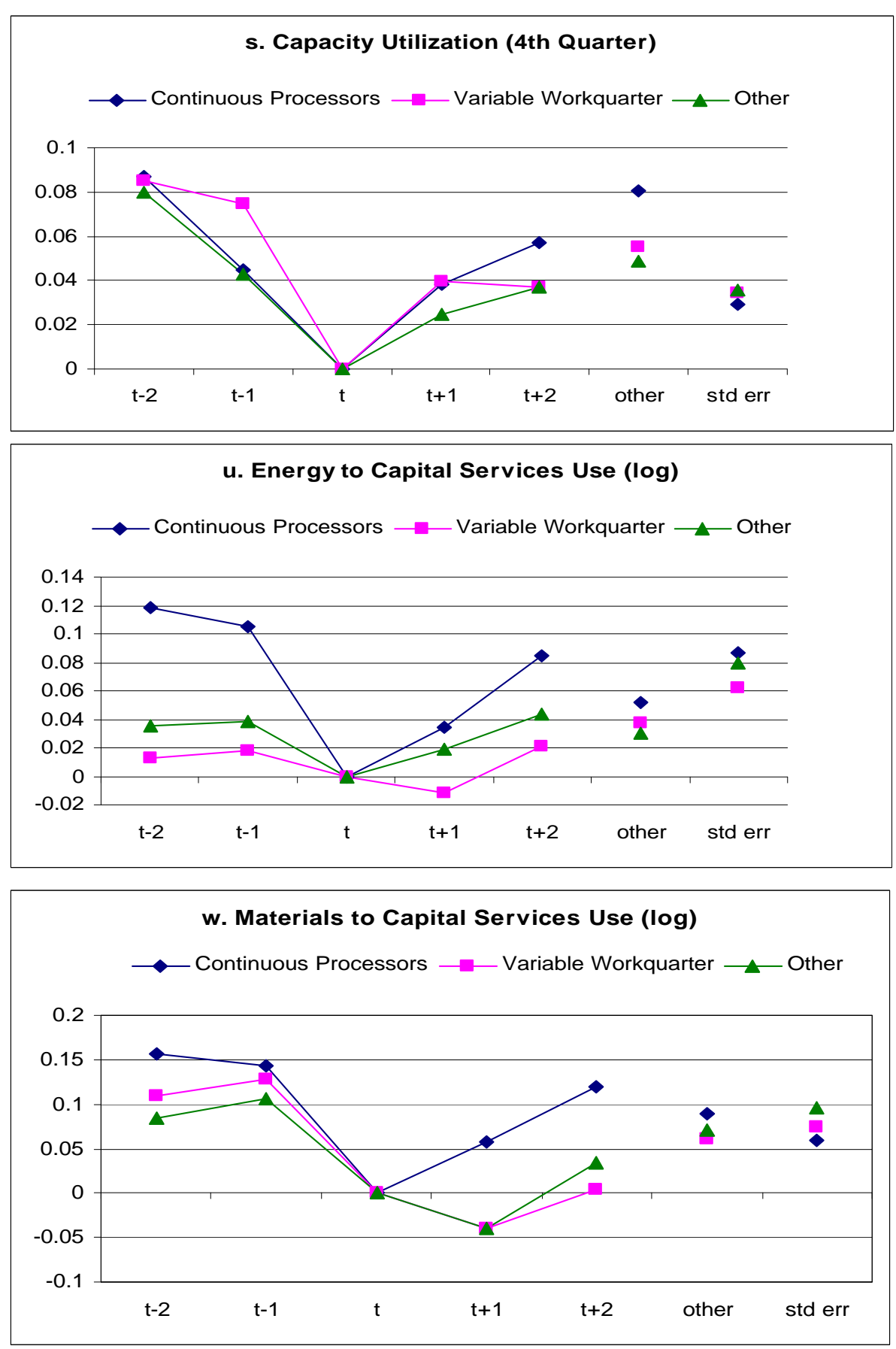
FIGURE 4: NEGATIVE EMPLOYMENT GROWTH (BALANCED-LRD SAMPLE)

\section{Frequency of Technology Class}

Event Population Total Population

$\begin{array}{lrrrr}\text { Continuous Processors } & 7,551 & 11.8 \% & 24,923 & 13.5 \% \\ \text { Variable Workquarter } & 31,158 & 48.5 \% & 82,842 & 44.8 \% \\ \text { Other } & 25,518 & 39.7 \% & 77,151 & 41.7 \%\end{array}$
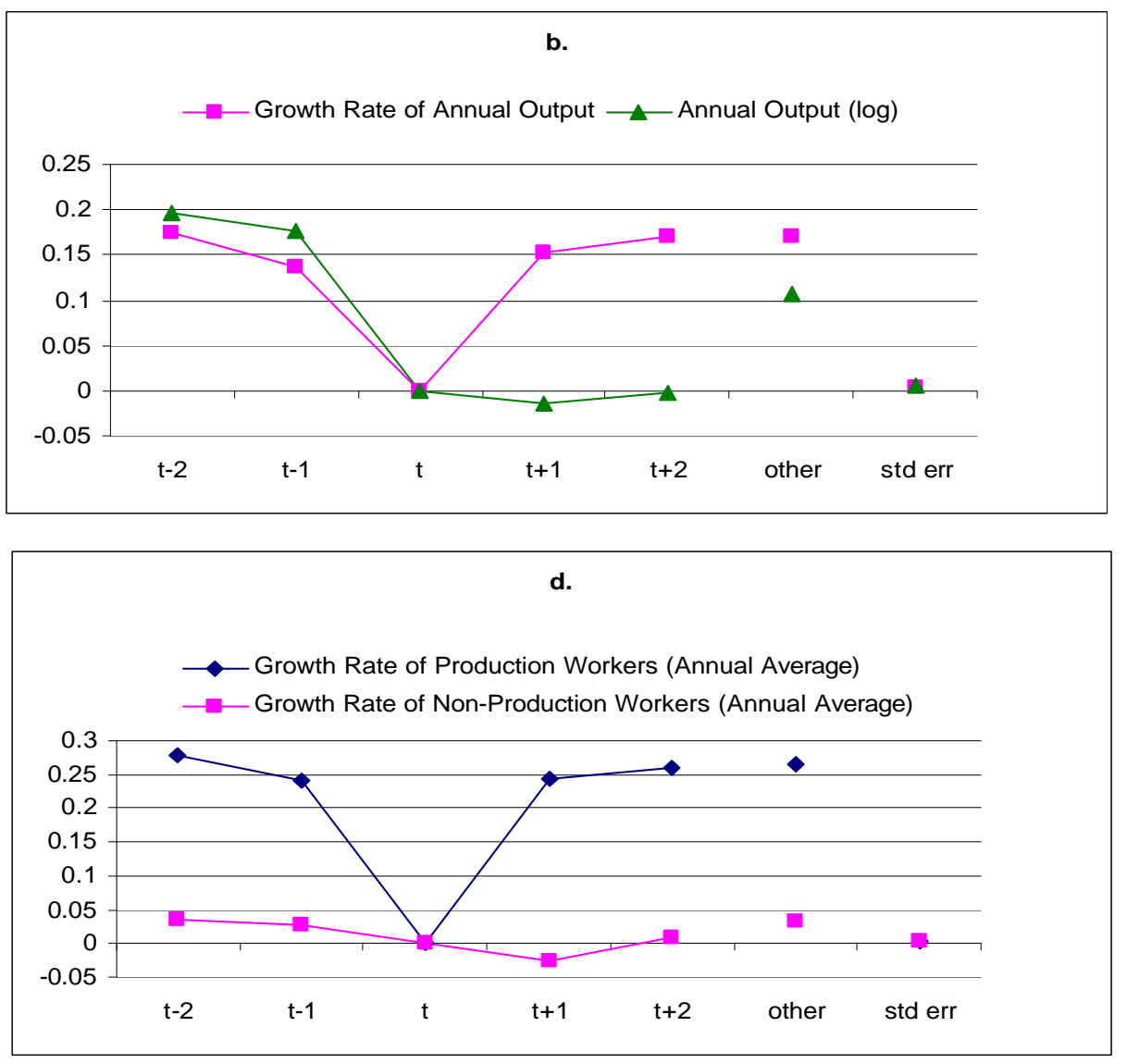

a. Distribution of Events

$\square$ Total $\square$ Continuous Processors $\square$ Variable Workquarter $\square$ Other

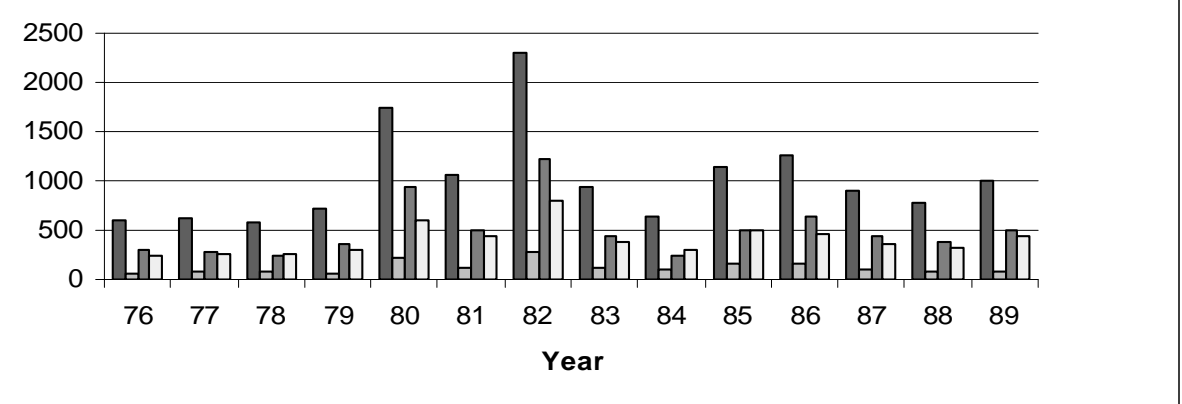

c.

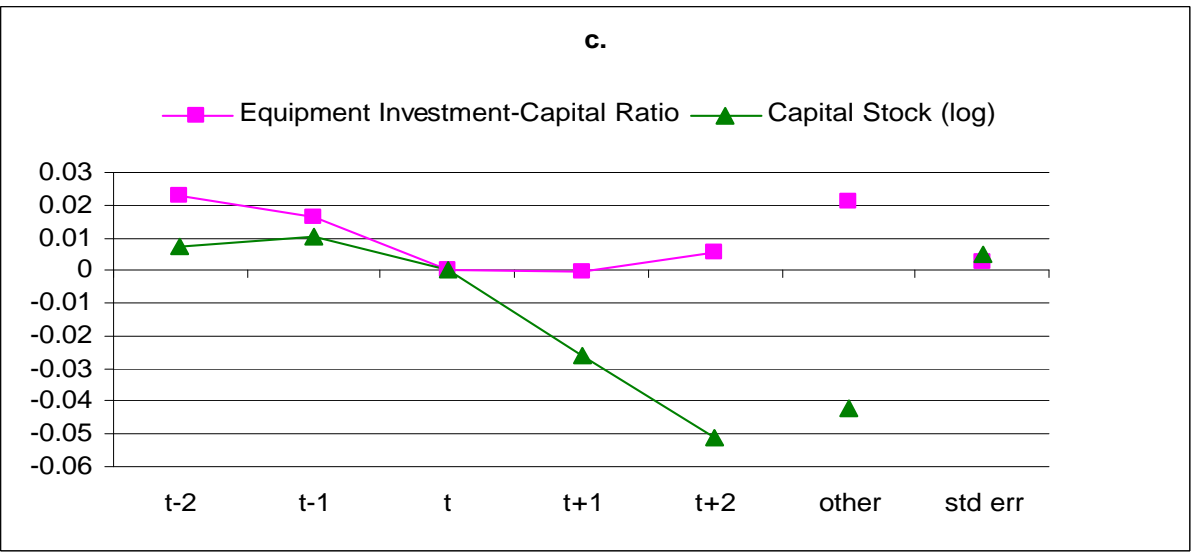

e.

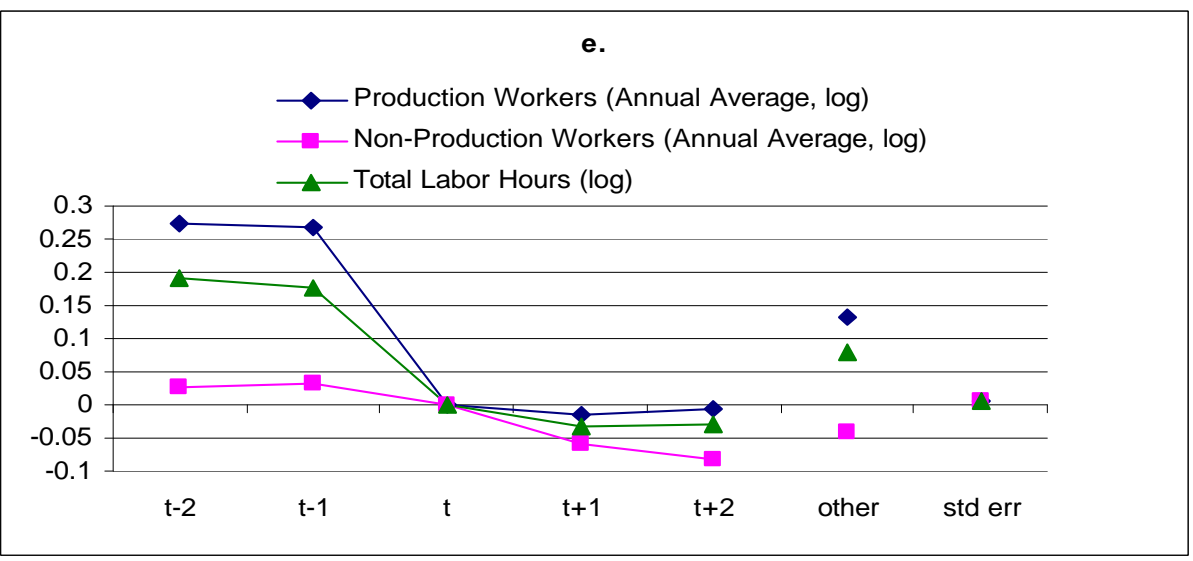


FIGURE 4: NEGATIVE EMPLOYMENT GROWTH (BALANCED-LRD SAMPLE)
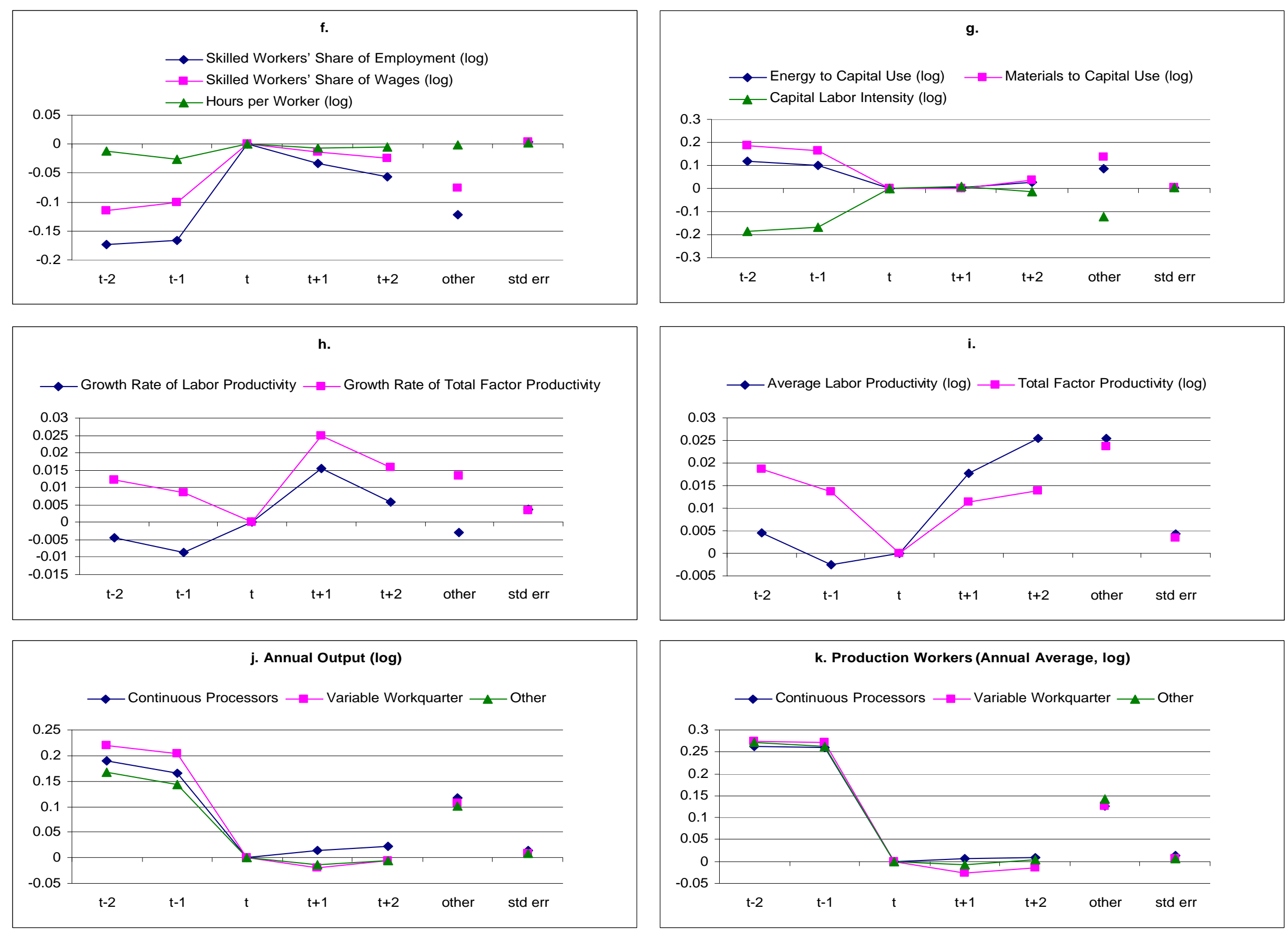
FIGURE 4: NEGATIVE EMPLOYMENT GROWTH (BALANCED-LRD SAMPLE)
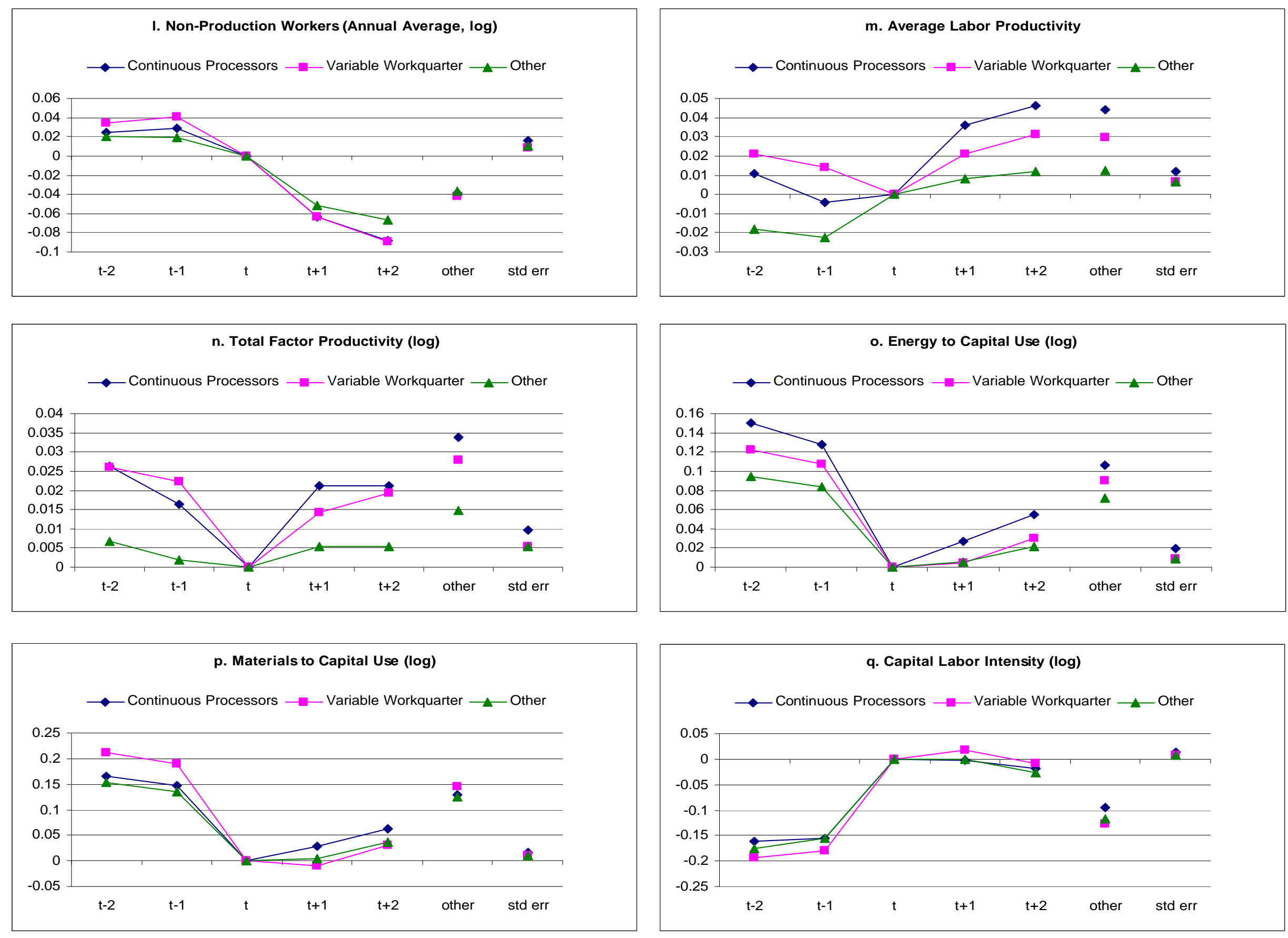
FIGURE 5: POSITIVE EMPLOYMENT GROWTH (MATCHED SAMPLE)

\section{Frequency of Technology Class}

Event Population Total Population

$\begin{array}{lllll}\text { Continuous Processors } & 138 & 13.4 \% & 2,611 & 27.8 \% \\ \text { Variable Workquarter } & 554 & 53.8 \% & 4,127 & 44.0 \% \\ \text { Other } & 337 & 32.8 \% & 2,639 & 28.1 \%\end{array}$
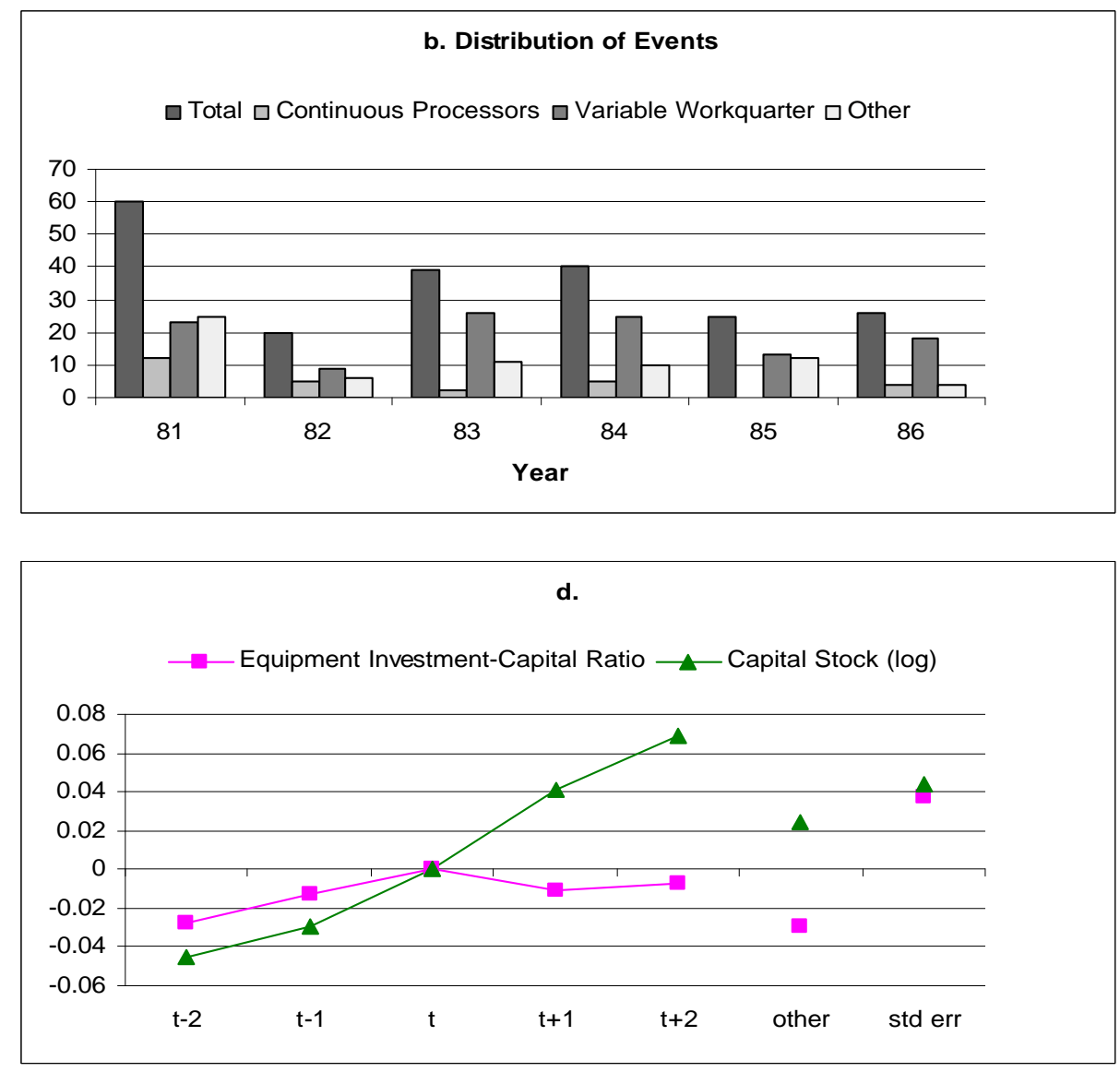
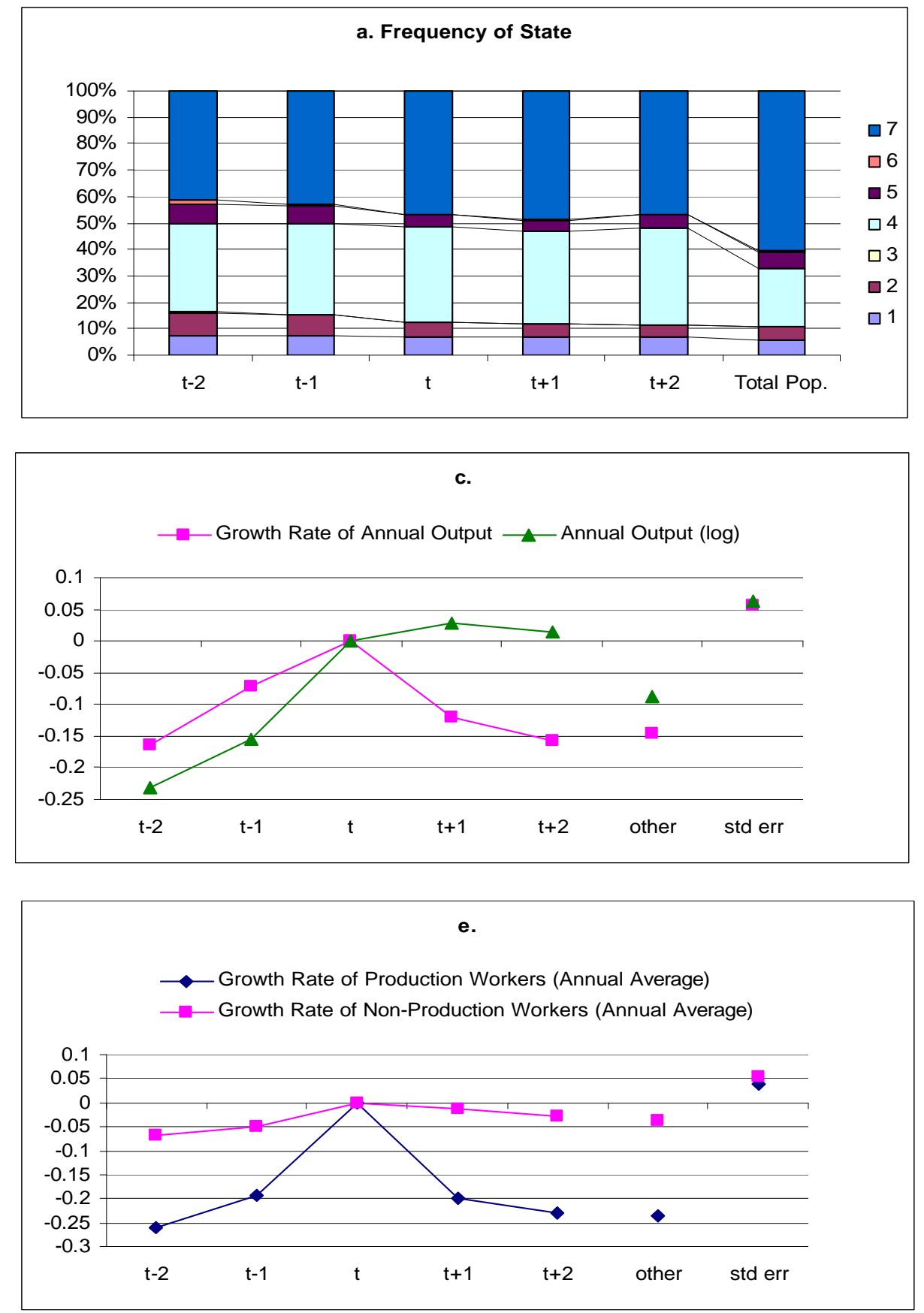

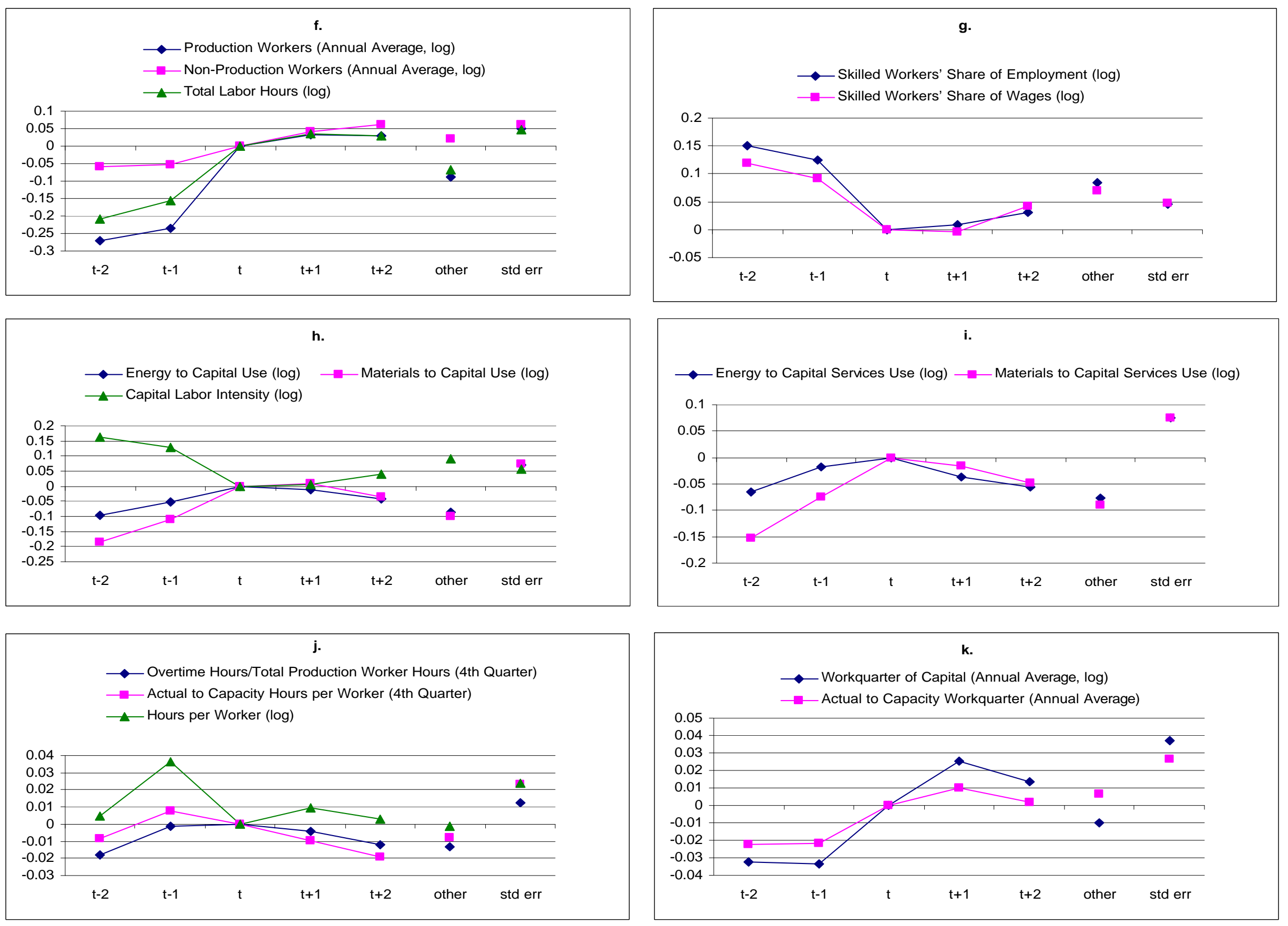
FIGURE 5: POSITIVE EMPLOYMENT GROWTH (MATCHED SAMPLE)
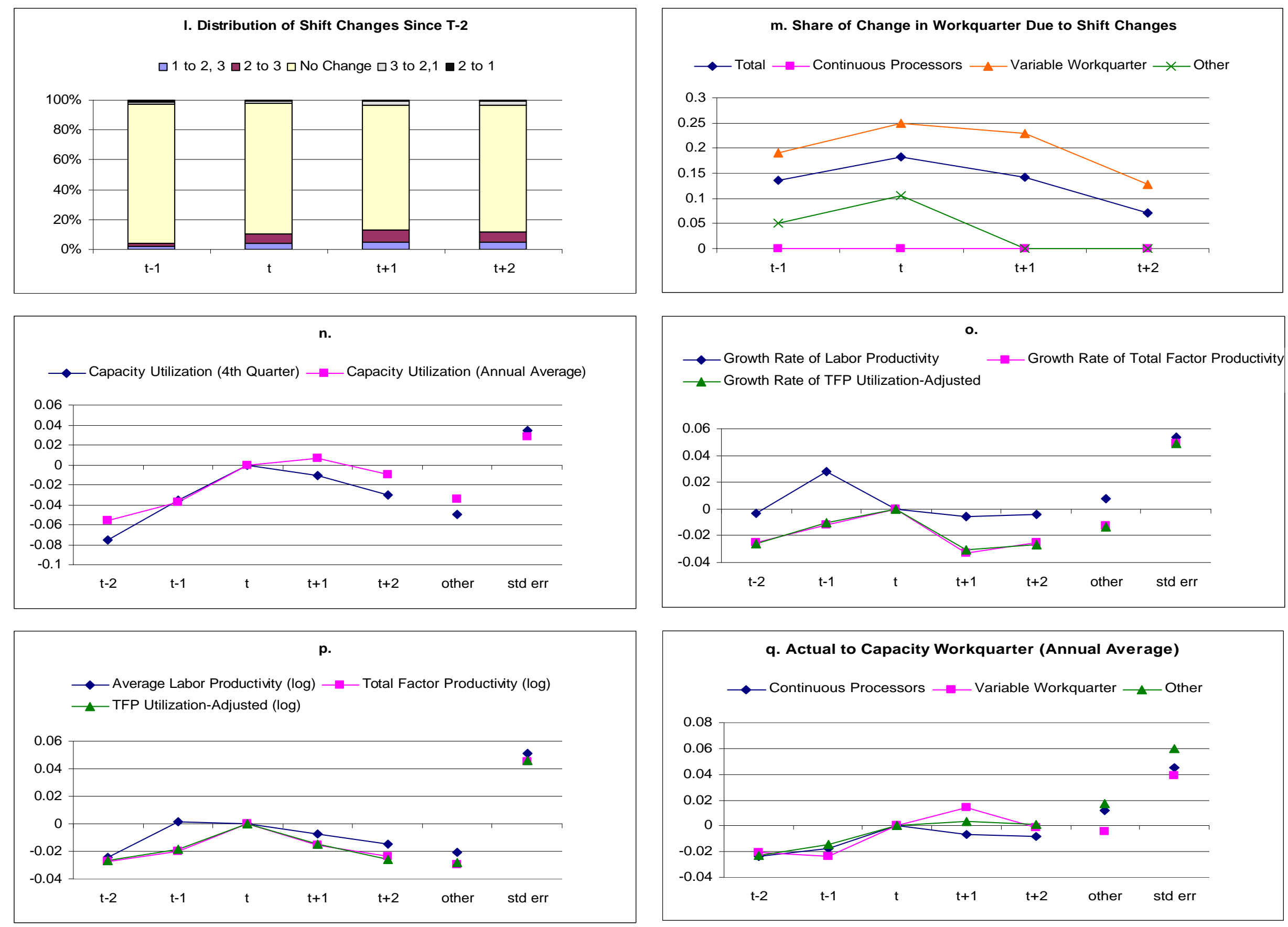
FIGURE 5: POSITIVE EMPLOYMENT GROWTH (MATCHED SAMPLE)
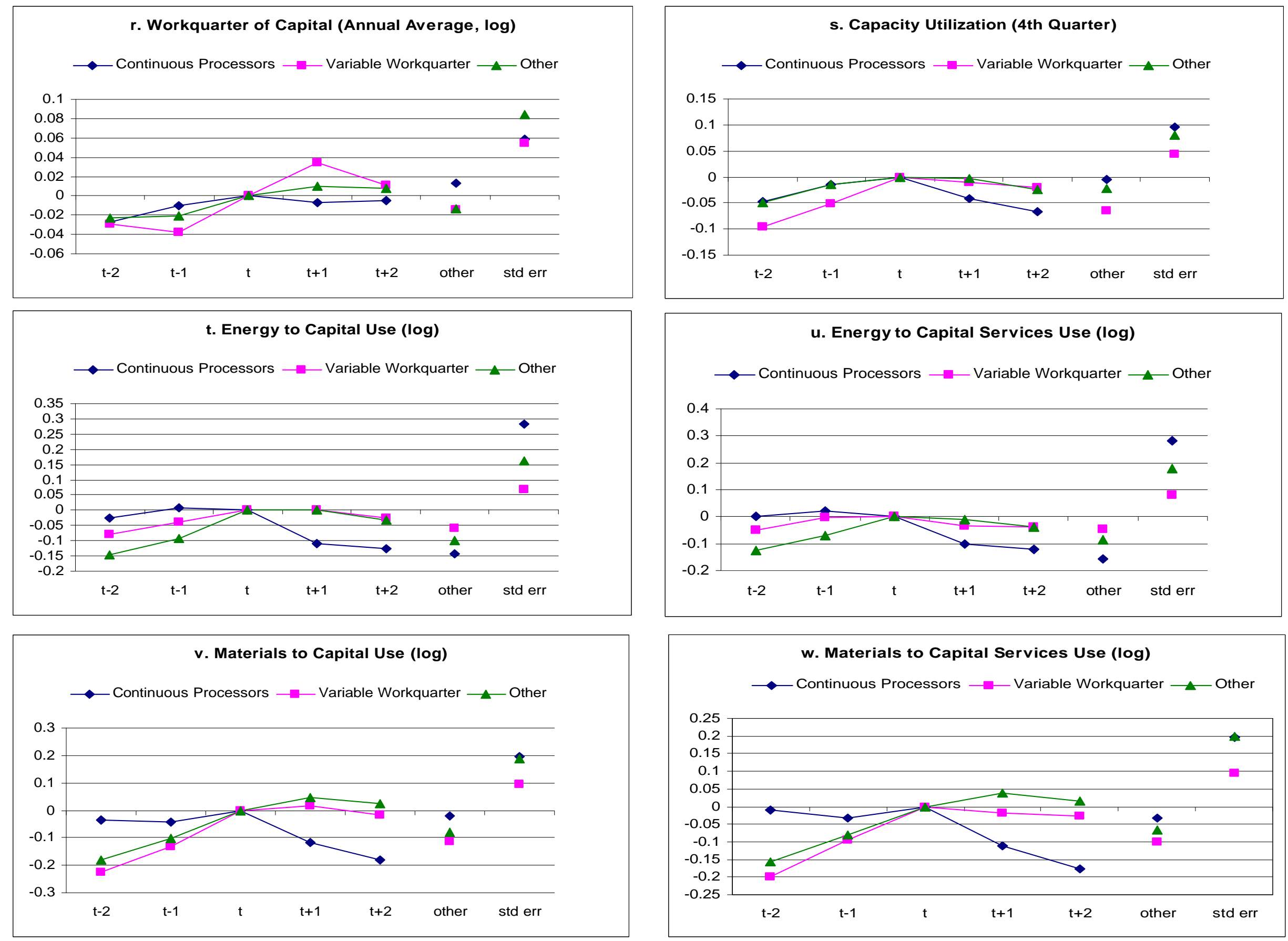
FIGURE 6: POSITIVE EMPLOYMENT GROWTH (BALANCED-LRD SAMPLE)

\section{Frequency of Technology Class}

\section{Event Population Total Population}

$\begin{array}{lrrrr}\text { Continuous Processors } & 5,058 & 9.1 \% & 24,923 & 13.5 \% \\ \text { Variable Workquarter } & 26,737 & 48.1 \% & 82,842 & 44.8 \% \\ \text { Other } & 23,792 & 42.8 \% & 77,151 & 41.7 \%\end{array}$
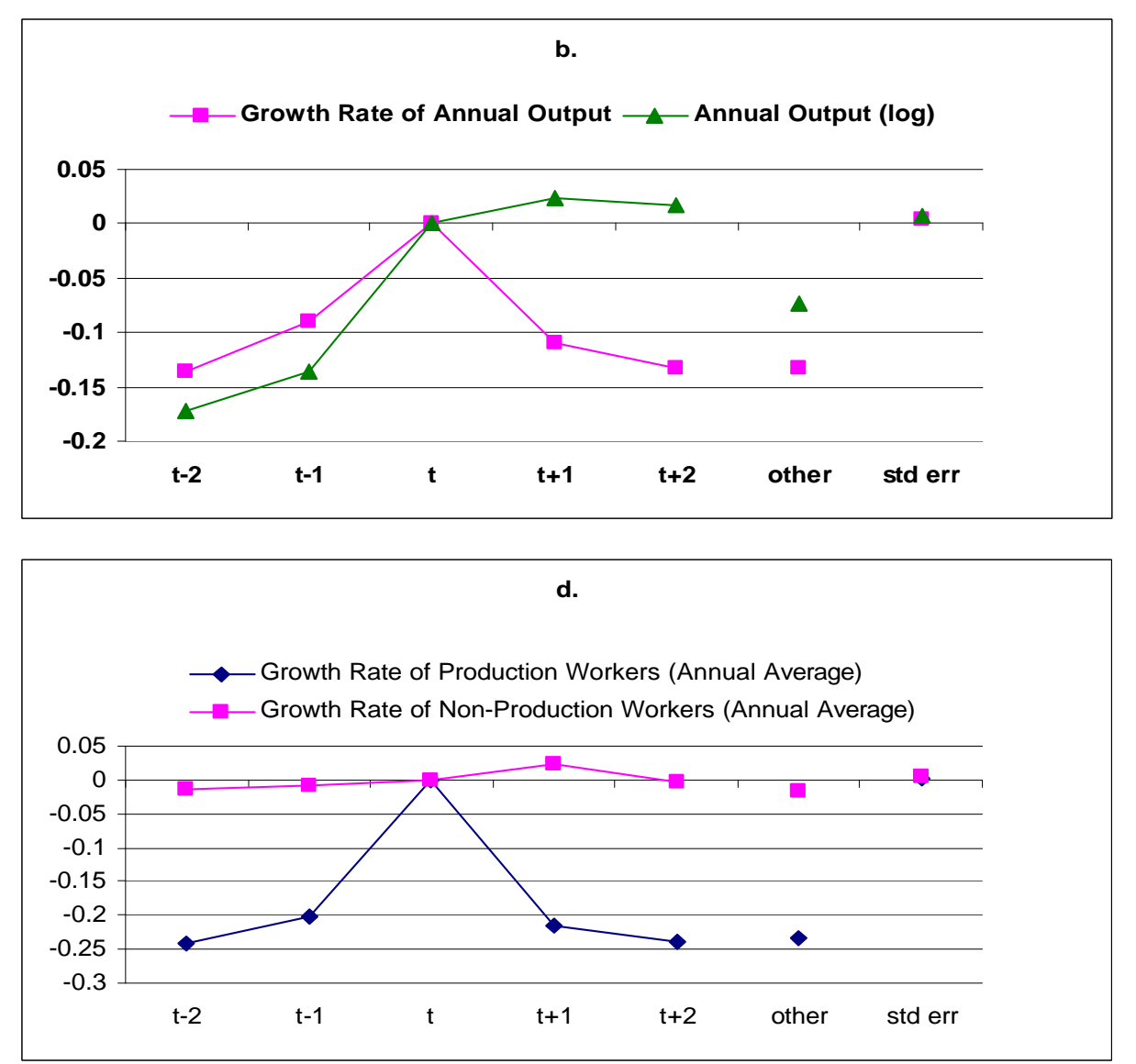

a. Distribution of Events

$\square$ Total $\square$ Continuous Processors $\square$ Variable Workquarter $\square$ Other

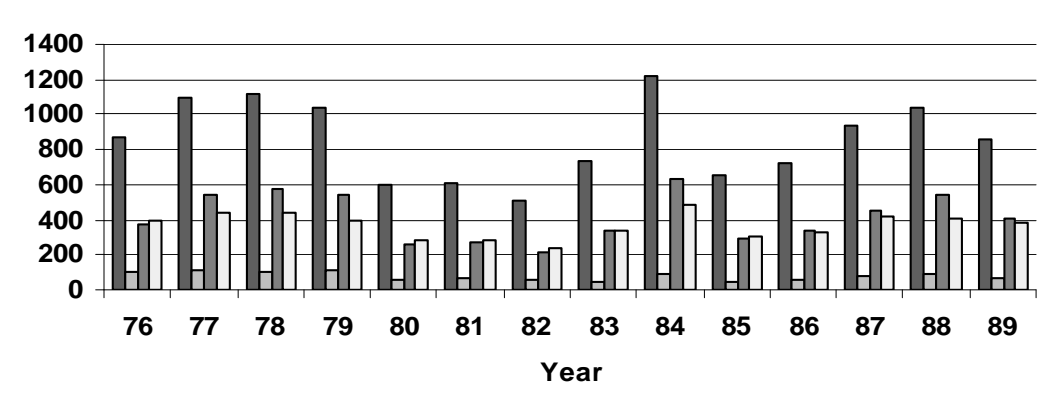

c.

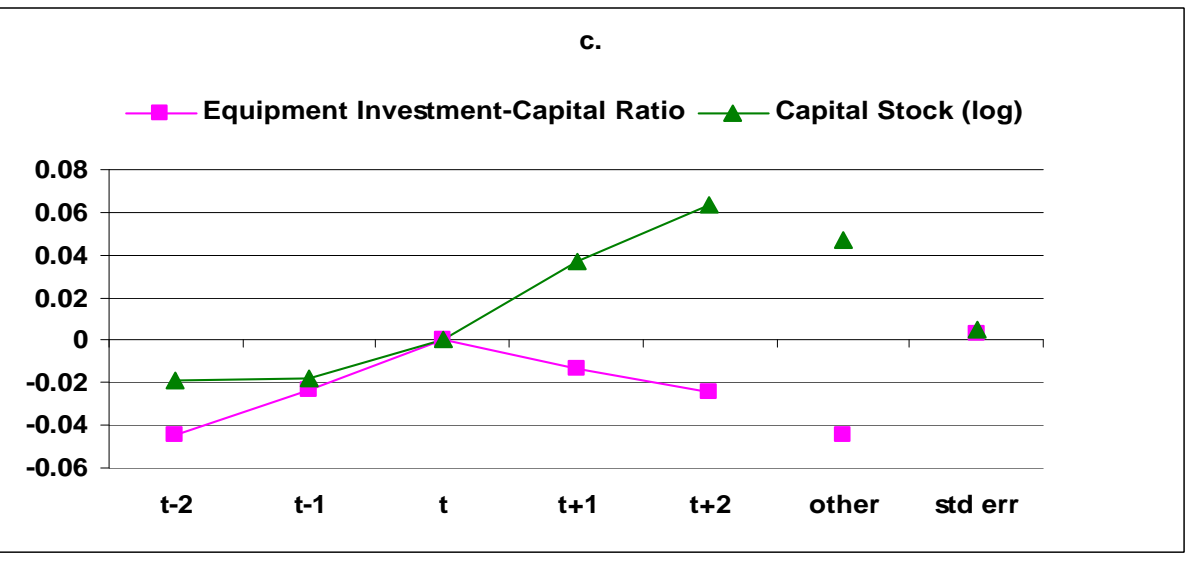

e.

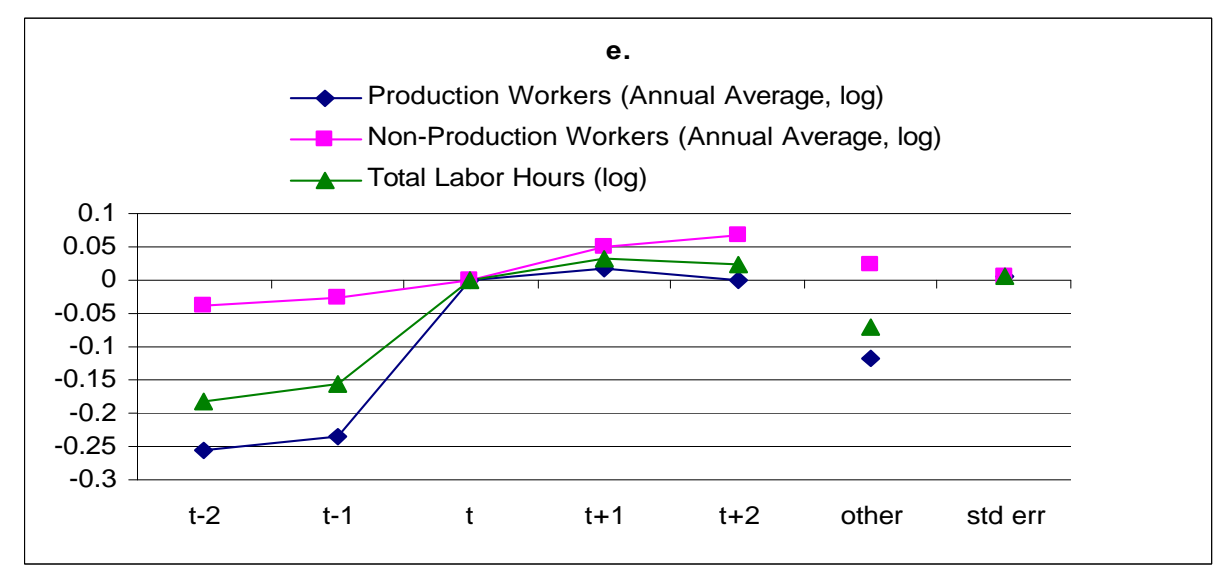


FIGURE 6: POSITIVE EMPLOYMENT GROWTH (BALANCED-LRD SAMPLE)
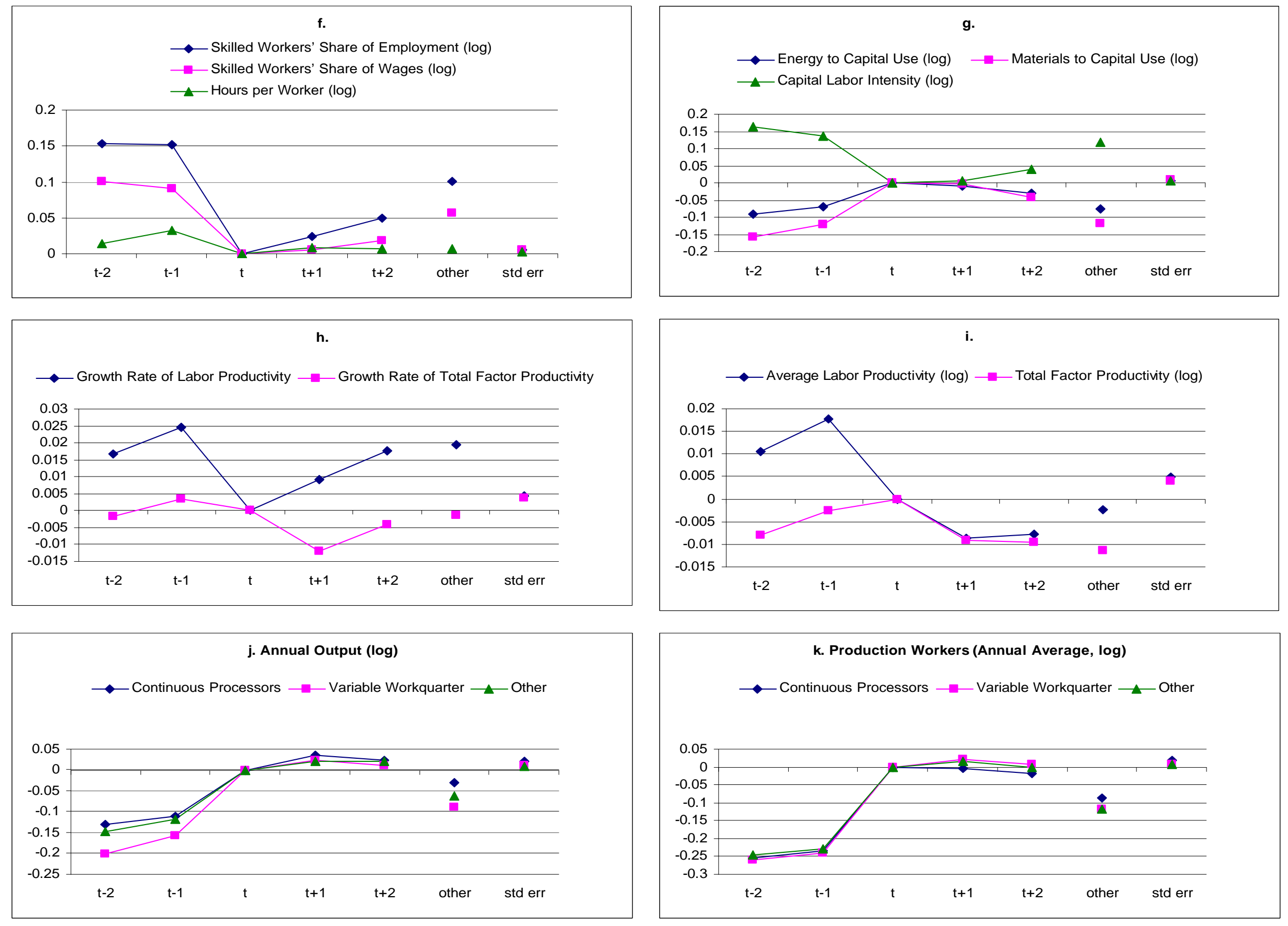
FIGURE 6: POSITIVE EMPLOYMENT GROWTH (BALANCED-LRD SAMPLE)
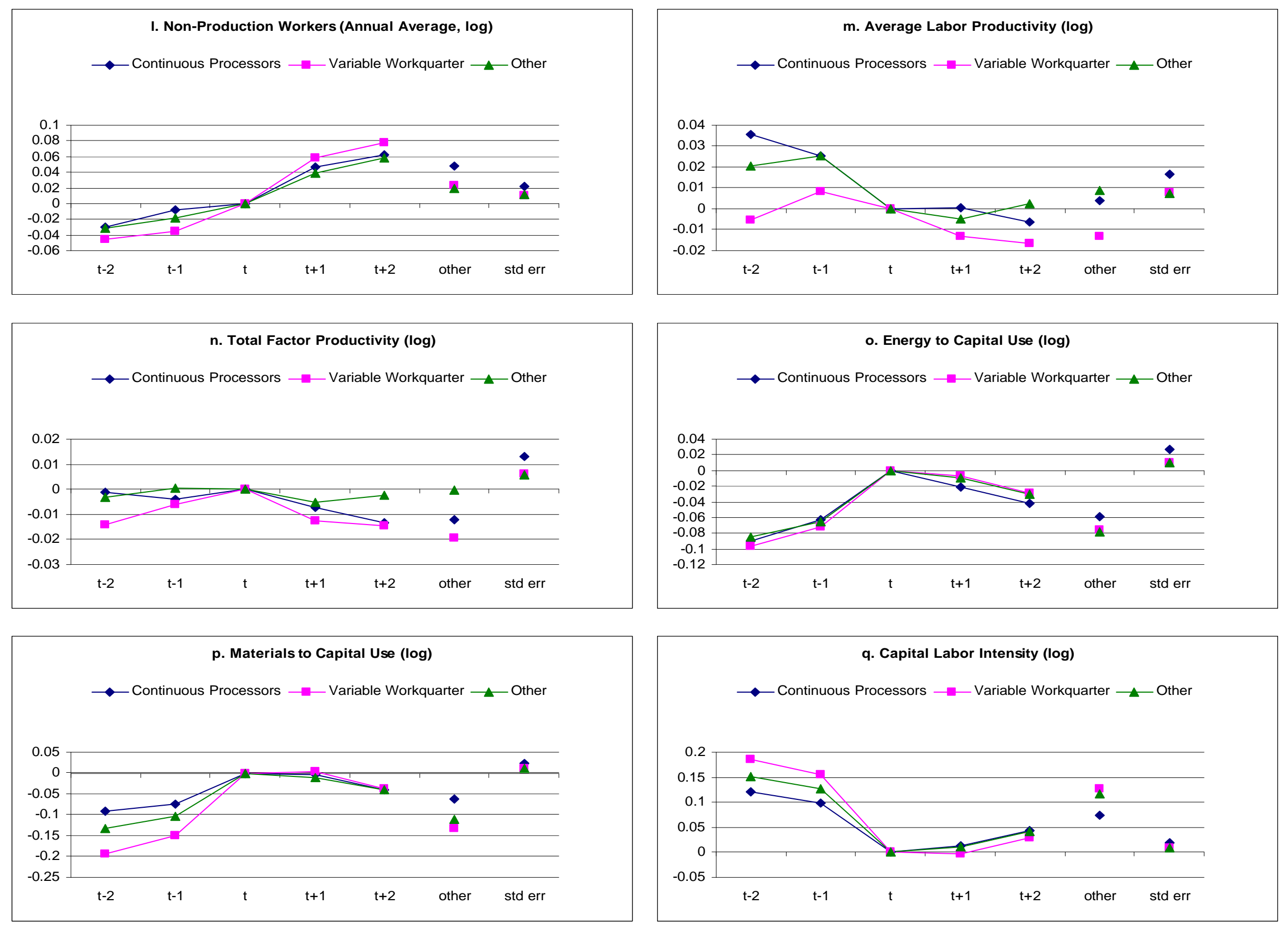